Review

\title{
Lewy Body Dementias: A Coin with Two Sides?
}

\author{
Ángela Milán-Tomás ${ }^{1}(0)$, Marta Fernández-Matarrubia ${ }^{2,3}$ and María Cruz Rodríguez-Oroz ${ }^{1,2,3,4, *}$ \\ 1 Department of Neurology, Clínica Universidad de Navarra, 28027 Madrid, Spain; AMILAN@UNAV.ES \\ 2 Department of Neurology, Clínica Universidad de Navarra, 31008 Pamplona, Spain; mfernandezma@unav.es \\ 3 IdiSNA, Navarra Institute for Health Research, 31008 Pamplona, Spain \\ 4 CIMA, Center of Applied Medical Research, Universidad de Navarra, Neurosciences Program, \\ 31008 Pamplona, Spain \\ * Correspondence: mcroroz@unav.es
}

Citation: Milán-Tomás, Á.;

Fernández-Matarrubia, M.;

Rodríguez-Oroz, M.C. Lewy Body Dementias: A Coin with Two Sides?. Behav. Sci. 2021, 11, 94. https:// doi.org/10.3390/bs11070094

Academic Editors: Scott D. Lane and Carmen Gasca-Salas

Received: 12 May 2021

Accepted: 15 June 2021

Published: 22 June 2021

Publisher's Note: MDPI stays neutral with regard to jurisdictional claims in published maps and institutional affiliations.

Copyright: (c) 2021 by the authors. Licensee MDPI, Basel, Switzerland. This article is an open access article distributed under the terms and conditions of the Creative Commons Attribution (CC BY) license (https:// creativecommons.org/licenses/by/ $4.0 /)$.

\begin{abstract}
Lewy body dementias (LBDs) consist of dementia with Lewy bodies (DLB) and Parkinson's disease dementia (PDD), which are clinically similar syndromes that share neuropathological findings with widespread cortical Lewy body deposition, often with a variable degree of concomitant Alzheimer pathology. The objective of this article is to provide an overview of the neuropathological and clinical features, current diagnostic criteria, biomarkers, and management of LBD. Literature research was performed using the PubMed database, and the most pertinent articles were read and are discussed in this paper. The diagnostic criteria for DLB have recently been updated, with the addition of indicative and supportive biomarker information. The time interval of dementia onset relative to parkinsonism remains the major distinction between DLB and PDD, underpinning controversy about whether they are the same illness in a different spectrum of the disease or two separate neurodegenerative disorders. The treatment for LBD is only symptomatic, but the expected progression and prognosis differ between the two entities. Diagnosis in prodromal stages should be of the utmost importance, because implementing early treatment might change the course of the illness if disease-modifying therapies are developed in the future. Thus, the identification of novel biomarkers constitutes an area of active research, with a special focus on $\alpha$-synuclein markers.
\end{abstract}

Keywords: Lewy body dementias; dementia with Lewy bodies; Parkinson disease dementia; diagnosis; biomarkers

\section{Introduction}

Lewy body dementia is an umbrella term that includes Parkinson's disease dementia (PDD) and dementia with Lewy bodies (DLB), which are two entities on a spectrum of Lewy body disease. The two disorders share many clinical and pathological features, including the deposition of widespread limbic and cortical Lewy bodies and Lewy neurites composed of aggregates of $\alpha$-synuclein ( $\alpha$-syn) [1] and loss of midbrain dopamine cells and cholinergic neurons in the ventral forebrain nuclei [2].

DLB is the second most common form of dementia after Alzheimer's disease (AD). However, previous studies have shown a wide prevalence variation, probably due to DLB being underdiagnosed [3]. In a systematic review of twenty-two studies addressing the prevalence and incidence of DLB [4], DLB accounted for 3.2-7.1\% of all dementia cases in the incidence studies, and the point and period prevalence estimates increased with age and ranged from 0.02 to 63.5 per 1000 persons. Nevertheless, these numbers probably underestimate the true prevalence and incidence of DLB because misdiagnosis as AD is common [3].

In addition to the common motor manifestations of Parkinson's disease (PD) (tremor, rigidity, akinesia), other non-motor manifestations, such as sensory abnormalities, autonomic dysfunction, and behavioral and cognitive changes, are common [5,6]. About 25\% of patients newly diagnosed with PD fulfill the diagnosis of mild cognitive impairment 
(PD-MCI) [7,8]; at follow-up (mean follow-up $23.5 \pm 10.3$ months), 33.3\% of the PD cognitively normal patients develop MCI and 4.8\% convert to PDD, resulting in an incidence rate of 123.5/1000 per year (95\% CI 70.3-202.2) [9]. Most individuals with PD have MCI or dementia with the progression of the disease [10-12], which occur in up to $83 \%$ of cases after 20 years of disease duration [13].

The diagnosis of PDD and DLB is challenging because many clinical manifestations and additional findings in the examinations overlap. However, reaching an early and accurate diagnosis is critical to disentangle the heterogeneity of these two entities, and to develop proper and specific clinical trials of neuroprotective therapies, thus providing an early optimal treatment and a correct prognosis to patients and caregivers. The purpose of this article is to provide an overview of the main neuropathological findings, clinical features, current diagnostic criteria, principal biomarkers, and management of DLB and PDD.

\section{Methods}

A literature search was performed using the PubMed database for January 1995 to January 2021 using the following disease-specific keywords- "Parkinson disease dementia," "Lewy body dementia," "Lewy body disorders" and "Lewy body disease" — together with one of the modality-specific keywords: "neuropathology," "diagnostic criteria," "prevalence," "behavioral features," "neuropsychiatric symptoms," "magnetic resonance imaging," "positron emission tomography," "single-photon emission computed tomography," "diffusion tensor," "diffusion-weighted," "quantitative susceptibility mapping", "proton spectroscopy," "polysomnography," "electroencephalogram," and "management." Acronyms, e.g., "PET" for "positron emission tomography," were entered as appropriate. Abstracts of studies written in English from 1995 to 2021 were reviewed and those with a small sample number (case reports and case series) were excluded. We included longitudinal cohorts, case-control studies, major reviews, and three ongoing clinical trials.

\section{Current Diagnostic Criteria for Parkinson's Disease Dementia and Lewy Body Dementia}

Table 1 shows the current diagnostic criteria for PDD and DLB. For the clinical diagnosis of both entities, dementia syndrome must always be present.

Table 1. Criteria for the clinical diagnosis of probable and possible dementia with Lewy bodies (DLB) and Parkinson's disease dementia (PDD).

\begin{tabular}{|c|c|c|c|}
\hline \multicolumn{2}{|r|}{ DLB $^{1}$} & \multicolumn{2}{|r|}{$\mathrm{PDD}^{2}$} \\
\hline $\begin{array}{l}\text { Central } \\
\text { features }\end{array}$ & $\begin{array}{l}\text { Essential for a diagnosis: Dementia, in early } \\
\text { stages with memory impairment, may not } \\
\text { necessarily occur but is usually evident with } \\
\text { progression. Deficits in tests of attention, } \\
\text { executive function, and visuoperceptual } \\
\text { ability may be especially prominent and } \\
\text { occur early. }\end{array}$ & Core Features (I) & $\begin{array}{l}\text { Essential for a diagnosis (both must be } \\
\text { present): Diagnosis of Parkinson disease } \\
\text { according to Queen Square Brain Bank } \\
\text { criteria and Dementia syndrome with } \\
\text { impairment in more than one } \\
\text { cognitive domain }\end{array}$ \\
\hline $\begin{array}{l}\text { Core clinical } \\
\text { features }\end{array}$ & $\begin{array}{l}\text { The first three typically occur early and may } \\
\text { persist throughout the course: } \\
\text { 1. Fluctuating cognition with pronounced } \\
\text { variations in attention and alertness. } \\
\text { 2. Recurrent visual hallucinations that are } \\
\text { typically well formed and detailed. } \\
\text { 3. REM sleep behavior disorder (may } \\
\text { precede cognitive decline). }\end{array}$ & $\begin{array}{l}\text { Associated clinical } \\
\text { features (II) }\end{array}$ & $\begin{array}{l}\text { 1. Typical profile of cognitive deficits (at } \\
\text { least two of the four core cognitive } \\
\text { domains): impaired attention (which } \\
\text { may fluctuate), executive, and } \\
\text { visuo-spatial functions, and impaired } \\
\text { free recall memory, which usually } \\
\text { improves with cueing. } \\
\text { 2. The presence of at least one } \\
\text { behavioral symptom (apathy, } \\
\text { depressed or anxious mood, } \\
\text { hallucinations, delusions, or } \\
\text { excessive daytime sleepiness) } \\
\text { supports the diagnosis of probable }\end{array}$ \\
\hline
\end{tabular}


Table 1. Cont.

\begin{tabular}{|c|c|c|c|}
\hline \multicolumn{2}{|r|}{ DLB $^{1}$} & \multicolumn{2}{|r|}{$\mathrm{PDD}^{2}$} \\
\hline & $\begin{array}{l}\text { One or more spontaneous cardinal } \\
\text { features of parkinsonism: bradykinesia, } \\
\text { rest tremor, or rigidity. }\end{array}$ & & $\begin{array}{l}\text { PDD; lack of behavioral symptoms, } \\
\text { however, does not exclude the diagnosis }\end{array}$ \\
\hline $\begin{array}{l}\text { Supportive } \\
\text { clinical } \\
\text { features }\end{array}$ & $\begin{array}{l}\text { Severe sensitivity to antipsychotic agents; } \\
\text { postural instability; repeated falls; syncope or } \\
\text { other transient episodes of unresponsiveness; } \\
\text { severe autonomic dysfunction, e.g., } \\
\text { constipation, orthostatic hypotension, } \\
\text { urinary incontinence; hypersomnia; } \\
\text { hyposmia; hallucinations in other modalities; } \\
\text { systematized delusions; apathy, anxiety, and } \\
\text { depression. }\end{array}$ & $\begin{array}{l}\text { None of the } \\
\text { group (III) features } \\
\text { present }\end{array}$ & $\begin{array}{l}\text { Features which do not exclude PDD, but } \\
\text { make the diagnosis uncertain: } \\
\text { 1. Co-existence of any other } \\
\text { abnormality which may by itself } \\
\text { cause cognitive impairment, but } \\
\text { judged not to be the cause of } \\
\text { dementia, e.g., presence of relevant } \\
\text { vascular disease in imaging } \\
\text { Time interval between the } \\
\text { development of motor and cognitive } \\
\text { symptoms not known }\end{array}$ \\
\hline $\begin{array}{l}\text { Indicative } \\
\text { biomarkers }\end{array}$ & $\begin{array}{l}\text { 1. Reduced dopamine transporter uptake } \\
\text { in basal ganglia demonstrated by } \\
\text { SPECT or PET. } \\
\text { 2. Abnormal (low uptake) } \\
\text { 123iodine-MIBG myocardial } \\
\text { scintigraphy. } \\
\text { 3. Polysomnographic confirmation of } \\
\text { REM sleep without atonia. }\end{array}$ & $\begin{array}{l}\text { None of the } \\
\text { group (IV) features } \\
\text { present }\end{array}$ & $\begin{array}{l}\text { Features suggesting other conditions or } \\
\text { diseases as cause of mental impairment, } \\
\text { which, when present, make it impossible to } \\
\text { reliably diagnose PDD: } 1 \text {. Cognitive and } \\
\text { behavioral symptoms appearing solely in } \\
\text { the context of other conditions such as } \\
\text { acute confusion due to (a.) systemic } \\
\text { diseases or abnormalities (b.) drug } \\
\text { intoxication } \\
\text { 2. Major Depression according to DSM IV }\end{array}$ \\
\hline
\end{tabular}

1. Relative preservation of medial temporal lobe structures on CT/MRI scan.

2. Generalized low uptake on

Supportive biomarkers SPECT/PET perfusion/metabolism scan with reduced occipital activity + / - the cingulate island sign on FDG-PET imaging.

3. Prominent posterior slow-wave activity on EEG with periodic fluctuations in the pre-alpha/theta range.
Probable: (a) $\geq 2$ core clinical features of DLB are present, with or without the presence of indicative biomarkers, OR (b). Only one core clinical feature is present, but with $\geq 1$

Diagnosis of probable or possible indicative biomarkers. Probable DLB should not be diagnosed on the basis of biomarkers alone.

DLB Possible: (a). Only one core clinical feature of DLB is present, with no indicative biomarker evidence, $\mathrm{OR}(\mathrm{b})$. $\geq 1$ indicative biomarkers is present but there are no core clinical features.
Supportive or indicative biomarkers
No supportive or indicative biomarkers are needed for the diagnosis of PDD as per Emre et al. (2007) diagnostic criteria.
Probable: (a) Core features: Both must be present; (b). Associated clinical features: Typical profile of cognitive deficits and the presence of at least one behavioral symptom (lack of behavioral symptoms, however, does not exclude the diagnosis); (c) None of the group III features present; (d) None of the group IV features present. Possible: (a) Core features: Both must be present (b). Associated clinical features: Atypical profile of cognitive impairment in one or more domains (e.g., fluent aphasia, or pure storage-failure type amnesia) and behavioral symptoms may or may not be present; OR (c) One or more of the group III features present, (d) None of the group IV features present
Diagnosis of probable or possible PDD 
Revised clinical diagnostic criteria for DLB were published in 2017 [14]. Major differences with the previous criteria [16] included distinguishing among clinical features and biomarkers; upgrading REM sleep behavior disorder (RBD) from a suggestive feature to a core clinical feature based on interim evidence; downgrading of antipsychotic (neuroleptic) hypersensitivity to a supportive feature based on reducing the frequency in prescribing D2 blocking antipsychotics in clinical practice [17]; and elimination of suggestive feature category. Advances in revised diagnostic criteria for DLB are supposed to improve diagnosis, but the impact of these new criteria is not yet known.

Consensus criteria for PDD were developed in 2007 [15]. PDD is diagnosed in the context of an established diagnosis of PD, and consists of identifying a profile of cognitive and behavioral changes consistent with PDD and excluding other potential factors (Table 1). The criteria require impairment in more than one cognitive domain, and emphasize that non-cognitive features such as hallucinations are common. The presence of at least one behavioral symptom contributes to support the diagnosis of probable PDD; however, the lack of behavioral symptoms does not exclude the diagnosis [17]. Whereas supportive and indicative biomarkers are included in the 2017 revised diagnostic criteria for DLB, current clinical criteria of PDD do not include biomarker information.

Although the progression of the symptoms primarily differentiates PDD from DLB, there are no well-founded reasons to define the time interval between the development of parkinsonism and the onset of dementia. However, to avoid diagnostic confusion in the clinical setting, the Movement Disorders Society Task Force recommends that the diagnosis of PDD should be made when dementia develops within the context of well-established PD, whereas a diagnosis of DLB is more appropriate when the diagnosis of dementia precedes or coincides within one year of the beginning of motor symptoms [15].

More recently, prodromal DLB diagnosis has become more common, and the updated research criteria for prodromal DLB suggests that if the order of parkinsonism and cognitive decline cannot be clearly established, then an initial diagnosis of prodromal DLB may be preferable (see Table 2) [18].

Table 2. Research criteria for the clinical diagnosis of probable or possible mild cognitive impairment due to Lewy body dementia (MCI-LB).

Essential for a diagnosis of MCI-LB is MCI defined by the presence of each of the following:

1. Concern by the patient, informant, or clinician regarding cognitive decline.

2. Objective evidence of impairment in one or more cognitive domains. The cognitive impairment may include any domain, but is more likely to be associated with attention-executive and/or visual processing deficits.

3. Preserved or minimally affected performance of previously attained independence in functional abilities, which do not meet the criteria for dementia.

Core clinical features:

1. Fluctuating cognition with variations in attention and alertness.

2. Recurrent visual hallucinations.

3. REM Behavior disorder.

4. One or more spontaneous cardinal features of parkinsonism: bradykinesia, rest tremor, or rigidity.

Supportive clinical features: Severe sensitivity to antipsychotic agents; postural instability; repeated falls; syncope or other transient episodes of unresponsiveness; prolonged or recurrent delirium; autonomic dysfunction, e.g., constipation, orthostatic hypotension, urinary incontinence; hypersomnia; hyposmia; hallucinations in other modalities including passage, and sense of presence phenomena; systematized delusions; apathy, anxiety, and depression.

\section{Proposed biomarkers}

a. Reduced dopamine transporter uptake in basal ganglia demonstrated by SPECT or PET.

b. Polysomnographic confirmation of REM sleep without atonia.

c. Reduced meta-iodobenzylguanidine (MIBG) uptake on myocardial scintigraphy

\section{Potential biomarkers of MCI-LB:}

a. Quantitative EEG showing slowing and dominant frequency variability.

b. Relative preservation of medial temporal lobe structures on structural imaging.

c. Insular thinning and gray matter volume loss on MRI.

d. Low occipital uptake on perfusion/metabolism scan. 
Table 2. Cont.

\begin{abstract}
Note: MCI plus supportive clinical features or potential biomarkers are insufficient to diagnose MCI-LB but may raise suspicion of it and prompt biomarker investigation, which may add weight to an existing MCI-LB diagnosis. MCI-LB is less likely in the presence of any other physical illness or brain disease including cerebrovascular disease, and sufficient to account in part or in total for the clinical picture, although these do not exclude an MCI-LB diagnosis and may serve to indicate mixed or multiple pathologies contributing to the clinical presentation.

Probable or possible mild cognitive impairment due to Lewy body dementia (MCI-LB):

- Probable MCI-LB can be diagnosed if: Two or more core clinical features of DLB are present, or only one core clinical feature is present, but with one or more proposed biomarkers. Probable MCI should not be diagnosed based on biomarkers alone.

- Possible MCI-LB can be diagnosed if: Only one core clinical feature of DLB is present, with no proposed biomarkers, or one or more of the proposed biomarkers is present, but there are no core clinical features.
\end{abstract}

Adapted from Mckeith et al. [18].

Although there is no DLB-specific assessment battery, some authors have explored suitable instruments, such as a composite risk score tool, to evaluate different clinical manifestations, which showed good outcomes in terms of the receiving operating characteristic curve for DLB vs. AD = 0.93 and for prodromal, MCI-DLB vs. MCI-AD = 0.96 [19]. Neuropsychological assessment serves an important role in providing objective evidence of cognitive impairment to support the clinical diagnosis of dementia in PD and DLB [14,15].

\title{
4. Diagnostic Approach
}

PD subjects who develop dementia do not need further complementary examinations as per the PDD diagnostic criteria [15] (see Figure 1). Like in DLB, a comprehensive neuropsychological evaluation including the assessment of specific cognitive domains (attention, memory, executive functions, language, construction, praxis, and visuospatial functions) is useful to assess the specific profile of cognitive impairment.

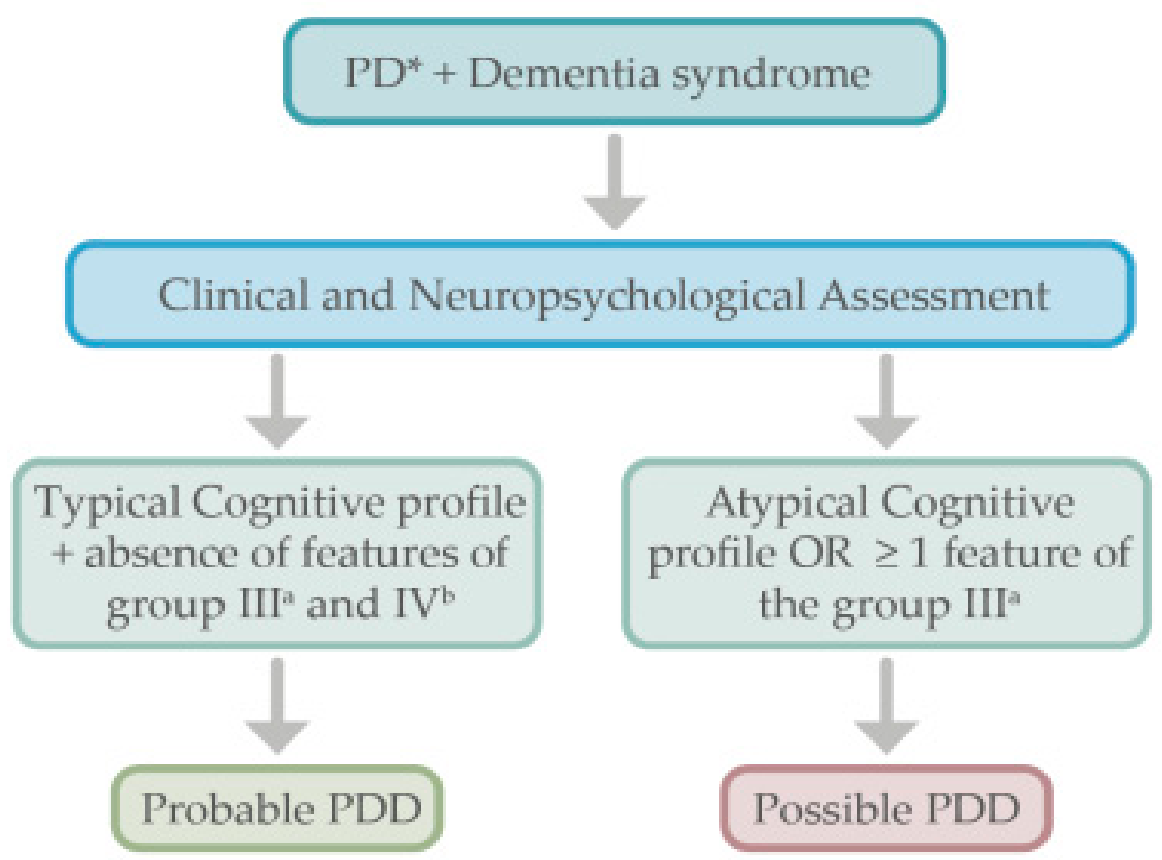

Figure 1. Proposed algorithm for the diagnostic approach in Parkinson's disease dementia. * Parkinson's disease diagnosis must be present. ${ }^{a}$ See Table 1 for the group III features. ${ }^{b}$ See Table 1 for the group IV features.

The diagnosis of DLB is based on the clinical history, physical evaluation, and neuropsychological assessment. When two core clinical features are present, the diagnosis of probable DLB is made, but in the case of only one core feature, the positivity of one or more indicative biomarkers (e.g., DAT-scan or ${ }^{123} \mathrm{IMBG}$ ) helps in the diagnosis of probable DLB. 
Moreover, for those patients in which dementia syndrome does not meet any of the core features of DLB, indicative biomarkers could be performed to establish the diagnosis of "possible" DLB or other neurodegenerative processes such as AD [20,21]. For those patients with atypical findings (e.g., a cognitive profile affecting memory rather than executive or visuospatial dysfunction), or for those patients with dementia in which only one of the core features of DLB is present, the use of functional imaging (e.g., DAT scans) or other indicative biomarkers may help in the diagnosis of probable DLB (see Figure 2). Supportive biomarkers such as FDG-PET, showing the typical "island sign," or a brain MRI with relative preservation of medial temporal lobe structures, increase the certainty of a DLB diagnosis [14].



Figure 2. Proposed algorithm for the diagnostic approach in Lewy body dementia. * Supportive biomarkers that help in the diagnostic evaluation but without clear diagnostic specificity. ${ }^{a}$ The cingulate island sign is only identifiable in FDG-PET, not in SPECT. DLB, dementia with Lewy bodies; DAT; dopamine transporter; F-DOPA, Flurodopa PET; SPECT, single photon emission computed tomography; PET, positron emission tomography; MIBG, iodine-123 -metaiodobenzylguanidine; PSG, polysomnography; MRI, magnetic resonance imaging; FDG-PET, fluoro-deoxy-glucose PET; EEG, electroencephalogram.

\section{Cognitive Profile of Lewy Body Dementias}

$\mathrm{MCI}$ is common in non-demented PD patients and the reported relative risk for developing dementia in PD compared to non-PD subjects ranges from 1.7- to 5.9-fold [15]. $\mathrm{MCI}$ and dementia in PD is heterogeneous, and combined different profiles (e.g., amnestic and non-amnestic, single versus multiple domains) have been described in PD-MCI [7]. However, from the perspective of progression to dementia, among others, two distinctive phenotypes are recognized: a fronto-striatal/executive pattern, which might be related to dysfunction in dopaminergic fronto-striatal networks [22], and a posterior cortical/visuospatial phenotype, which may involve changes in cholinergic transmission [2,23], which has been shown to be more correlated with cognition decline in LBD [23-25].

The impaired cognitive domains in PDD and DLB mostly include attention, memory, visuo-spatial, constructional, and executive functions, predominating the last one 
in LBD compared to AD [26,27]. LBD patients tend to perform worse in all perceptual scores compared to AD. This is consistent with previous neuroimaging studies reporting hypoperfusion or hypometabolism in cortical areas involving visual processing in PDD and DLB [23-25,28,29], which has been included as a supportive biomarker of DLB [14].

Smirnov et al. (2020) [30] published a study focusing on domain-specific patterns of cognitive impairment and trajectories of decline that differ in patients with PDD and autopsy-confirmed DLB. The authors found that DLB and PDD were more impaired and declined more rapidly than in $\mathrm{AD}$ in the visuospatial domain, whereas memory was more impaired in AD compared to DLB and PDD. However, this study also observed a greater impairment and more rapid decline of executive function in PDD than in DLB, whereas language and verbal memory dysfunction were more prominent in DLB and AD than in PDD in the late stages of the disease. Although there is also evidence of verbal and non-verbal memory deficits in PDD and DLB [27,31], these are mostly related to executive dysfunction (e.g., observed improvement in recall with cueing, which relates to a retrieval problem rather than to encoding and storage deficits as occurs in AD). However, some authors have shown possible different patterns of verbal learning and memory deficits in PDD versus DLB [32]. This might be due to a higher frequency of concomitant AD pathology in DLB compared to PDD, which may influence the cognitive profile to more closely resemble that of AD in DLB cases.

Cognitive fluctuations with variations in attention and alertness constitute a core clinical feature of DLB. They consist of episodes of spontaneous alterations in cognition, attention, and arousal, leading to frequent daytime drowsiness, naps during the day, or perturbed flow of ideas. Although more frequent and severe in DLB patients $[33,34]$, fluctuations in cognition can also be present in PDD. In fact, "impaired attention which may fluctuate" is included as an associated clinical feature in the diagnostic criteria for the diagnosis of probable and possible PDD. Cognitive fluctuations can be hard to differentiate from toxic-metabolic processes and to quantify $[35,36]$. Some scales and questionnaires have been proposed for this purpose $[36,37]$. The updated criteria for the diagnosis of DLB recommend that at least one measure of fluctuations in cognition should be documented when applying its criteria [14].

Regarding the setting of diagnosis, it is worth mentioning that although many cognitive features appear to be similar in DLB and PDD, visuoperceptual and visuoconstructional functions and verbal and visual memory may be worse in DLB compared to PDD [38].

\section{Behavioral and Neuropsychiatric Manifestations of Lewy Body Dementias}

Neuropsychiatric manifestations are common in LBD patients. Depression, anxiety, and apathy are frequent in PDD and DLB [39-43], and they are included as supportive and associated features of both entities (Table 1). They may share a similar substrate, with depression being one of the most studied non-cognitive psychiatric disorders in PD, occurring in up to $50 \%$ of PD patients at some point in the course of their illness [42]. Depression is also linked to cognitive impairment $[44,45]$. Moreover, premorbid depression has been shown to be significantly more common in PD patients than in those without a diagnosis of PD $[6,46,47]$, preceding the motor symptoms and possibly dementia diagnosis of LBD $[6,43]$. Depression in DLB is also very frequent, with a prevalence of approximately $28 \%$ [48], and overall, depression in LBD is more frequent when compared to AD [49].

Apathy, defined by reduced initiative and motivation, appears to be equally common in PDD and DLB, reported in 54\% of PDD patients [50] and in 57\% of DLB [51]. Moreover, apathy appears to be associated with more serious symptomatology in DLB and faster cognitive decline [52]. Regarding anxiety, comparisons of its prevalence in PDD and DLB are lacking [38], but appear to be worse in DLB compared to in AD [53].

The psychosis spectrum in PD was recently reviewed [54] and includes minor experiences or hallucinations, such as passage and presence hallucinations or illusions in the early stages of PD [40], and well-formed complex recurring visual hallucinations with other modalities of hallucinations and delusions in later PD stages. The presence of cognitive 
impairment, depression, and dopaminergic use have been described as risk factors for hallucinations [55], and its phenomenology in PDD and DLB is very similar, with the majority of patients experiencing recurrent, complex visual hallucinations-seeing adults or small children, deceased family members, or small animals [1]. Visual hallucinations are usually more frequent and severe in DLB than in PDD (76\% vs. 54\%) [43], whereas auditory and other modalities of hallucinations are less prevalent in both entities [56,57]. Although hallucinations in PD may be triggered by the use of dopaminergic therapies, they can occur in drug-naïve PD patients [58]; however, they appear more often in DLB spontaneously [39].

A study analyzed the utility of pareidolias, measured by the Pareidolia test, as a surrogate indicator of visual hallucinations in patients with DLB [59]. The authors found that pareidolic responses were observed more frequently in patients with DLB than AD or healthy controls, and were detected even in patients without visual hallucinations. Thus, they proposed that pareidolic responses could be a possible predictive marker of DLB. In other study including PD patients without dementia [60], authors found that the number of pareidolic illusions correlated with hypometabolism in the bilateral temporal, parietal, and occipital cortices, which may suggest that posterior cortical dysfunction could be a common neural substrate of pareidolia and visual hallucinations. However, the test has not been properly assessed in PDD, so its utility as a diagnostic tool is not known.

In summary, although behavioral and neuropsychiatric symptoms are common in both PDD and DLB, most of the studies have shown that some of them, such as visual hallucinations and delusions, are more prevalent and severe in DLB compared to PDD [39,43]. Mood disturbances such as depression or apathy appear to be equally common in both disorders, but these are higher than in $\mathrm{AD}$ population. The use of questionnaires and other tools assessing neuropsychiatric symptoms in patients with LBD is relevant to obtain an adequate characterization of these manifestations and may help in the diagnosis.

\section{From Neuropathology to the Clinical Spectrum of Lewy Body Dementias}

PDD and DLB are clinical syndromes characterized by the neuropathological accumulation of misfolded $\alpha$-syn aggregates that form intraneuronal Lewy bodies and Lewy neurites. Different studies $[16,61,62]$ have reported that cortical or diffuse, or limbic, Lewy bodies (LB) and Lewy neurites correlate well with dementia in PD, indicating a caudal to rostral spread of this pathology from the brainstem to cerebral cortex. Staging systems of $\alpha$-syn pathology based on these observations have been proposed for PD [63] and DLB [64].

Accumulating evidence indicates that other pathologies are also present in patients with LBD. Superimposed AD-associated neuropathological changes (fibrillary amiloid $\beta$-protein, $A \beta$, and intraneuronal tangles consisting of hyperphosphorilated tau, $p$-tau) are common in DLB and PDD, with up to $50 \%$ of PDD patients showing severe AD-type pathology [65]. Larger study cohorts [65-67] have shown a correlation and synergistic effects between both cortical Lewy and AD-type pathologies, with higher cortical A $\beta$ accumulation implying faster progression to dementia [66,68]. A potential mechanism for this synergy is through phosphorylation. $\alpha$-syn can induce tau hyperphosphorylation, thereby promoting neurofibrillary tangle formation, and vice versa [68-73]. Moreover, the frequency and severity of $A \beta$ and tau pathology in the midbrain across the LBDspectrum have been shown to be located between those of controls and $A D$, with $A \beta$ in the tectum/tegmentum [74] and the striatum [75] being associated with dementia. Hepp et al. (2016) [67] showed that $A \beta$ pathology was more often observed in the entorhinal cortex, amygdala, and putamen in DLB versus PDD patients. In contrast, PDD patients had $A \beta$ pathology more frequently in the temporal cortex and striatum versus PD patients without dementia, suggesting that the load and extent of $A \beta$ pathology may contribute to cognitive dysfunction in PDD. One of the limitations of these studies is the lack of detailed neuropsychological assessments; therefore, conclusions regarding the relationship between specific cognitive disturbances and the regional prevalence and severity of $A \beta$ pathology are not available. 
In patients with PDD, the hippocampus shows a higher density of Lewy pathology $[1,76]$. Although some authors have suggested that high neocortical and limbic LB burden is the only independent predictor of dementia in DLB [72,73], others considered ADrelated pathology to be more important in the decline of cognition in LBD [68,71,72,77-79].

A systematic review analyzing the contribution of $A \beta$ deposition (measured by amyloid PET) on the cognition of PD [80] supported the notion of $A \beta$ as an independent predictor of impaired cognition in the setting of PD. Correlations have also been shown between $\mathrm{A} \beta$ deposition in multiple cortical regions (e.g., frontal, posterior cingulate, temporal, parietal, and occipital) with lower performance in a test involving attention, working memory, and visual processes, and attentional processing in PD without dementia [81]. From both clinical and pathological perspectives, LBDs are heterogeneous disorders, and different studies indicate that the cognitive decline and related symptoms are not only a consequence of $\alpha$-syn induced neurodegeneration, but also of mixed pathologies contributing to the overall deficits $[68,69,71,82,83]$.

Despite many similarities between PDD and DLB, some pathological differences have been demonstrated $[39,84]$, including less severe and less extended $A \beta$ load and lower tau load in the cortex and striatum in PDD compared to DLB $[39,85,86]$; and higher A $\beta$ load in the cortex and claustrum $[69,77]$, and in the entorhinal cortex, amygdala, and putamen in DLB [67]. Moreover, an important contribution of the presence of striatal A $\beta$ in the cognition of PD was shown when compared to cortical $\beta$-amyloidopathy alone $[75,87]$. Other differences include a more severe $\alpha$-syn load in the amygdala in DLB compared to PDD [88]. In PD, the highest load of $\alpha$-syn is found in the cingulate cortex, basal forebrain, and hippocampus $[69,76,89]$, with a higher deposition in the claustrum rising progressively from PD without dementia to PDD and DLB [88]. Moreover, hyperphosphorylated tau (p-tau) in LBD has been shown to be significantly lower than in AD but significantly higher than in controls [74], and may display a different pattern in DLB vs. PDD [69]. Global tau indices independently predicted dementia in PD cases in one study [90], whereas in two other studies authors did not find such an association [65,77]. Finally, other co-pathologies, including cerebrovascular disease and TDP-43, are also likely to influence clinical features and progression in LBD [91,92].

\section{Biomarkers for Lewy Body Dementias}

Direct biomarker evidence of Lewy body-related pathology is not yet available for clinical diagnosis; however, several methods have been used to support the clinical diagnosis of PDD and DLB. Neuroimaging techniques, fluid biomarkers, and potential (research) biomarkers are discussed in the following paragraphs. A summary of the main results of these biomarkers in LBD can be seen in Table 3.

\subsection{Magnetic Resonance Imaging in Lewy Body Dementias \\ 8.1.1. Structural Magnetic Resonance Imaging}

Structural brain changes can be assessed using magnetic resonance imaging (MRI) and computed tomography (CT), providing a measure of cerebral atrophy in PDD and DLB. The following MRI sequences are commonly used: T1, T2, T2* $2^{*}\left(\mathrm{R}^{*}=1 / \mathrm{T} 2^{*}\right)$-weighted, susceptibility-weighted, proton-density-weighted, fluid-attenuated inversion recovery, and neuromelanin-sensitive sequences.

Voxel-based morphometry (VBM) studies in PDD have identified diffuse and heterogeneous patterns of cortical atrophy involving the occipital, temporal, right frontal, and left parietal lobe in comparison to controls and with PD without dementia [93-96], but they could be part of a common brain network centered on the hippocampi as per lesion network mapping [97]. Cortical thickness in the right precentral, superior frontal gyri, and the anterior cingulate cortex [98], and less gray matter (GM) volume in the prefrontal areas, insular cortex, and caudate nucleus [99,100], together with hippocampal atrophy, were observed in PD patients who developed dementia during follow-up [101]. VBM and cortical thickness has also been evaluated in DLB compared to AD, healthy controls, 
and PDD [102-108]. Although localization of GM reductions in DLB relative to PDD vary among different studies, Beyer et al. (2007) [93] reported greater GM reductions in the temporal, parietal, and occipital lobes in DLB compared to PDD. In addition to temporal and parietal atrophy, occipital and striatal GM reductions in DLB have also been reported [102].

Studies focusing on prodromal cases of LBD have shown that preserved hippocampal volumes are associated with an increased risk of probable DLB competing with AD dementia, which could help in the differential diagnosis of both entities [108], and it has been included as a supportive diagnostic feature of DLB [14]. In the case of PD, low hippocampal volume was described as a major factor predicting the development of mild cognitive impairment and dementia [101].

Diffusion tensor imaging (DTI) has shown widespread reduced fractional anisotropy (FA) in PDD when compared with cognitively normal PD patients and controls, compromising the main tracts (the superior and inferior longitudinal, inferior fronto-occipital and uncinate fasciculi, the cingulum, the corpus callosum, corona radiata, the anterior limb of the internal capsule, and the hippocampus) [109-114]. Cognitive performance strongly co-related to DTI metrics in the most anterior (projecting to the prefrontal cortex) and most posterior (callosal) sections, which may contribute to "fronto-striatal" and "posterior cortical" types of cognitive deficits seen in PD, respectively [115]. In DLB, increased mean diffusivity (MD) was found to be similar to AD and included clusters in the bilateral parahippocampal gyri (hippocampal cingulum) and left cingulate gyrus (frontal), but no correlation between FA and episodic memory in AD or DLB was found [116]. Other studies have evaluated the changes of FA in PD and DLB with and without hallucinations [117,118], and comparing DLB to AD [119]. However, the majority did not compare PDD with DLB [120], with one study showing that FA in patients with DLB was significantly decreased in bilateral posterior temporal, posterior cingular, and bilateral visual association fibers extending into occipital areas $(p<0.001)$ [121].

Changes in the substantia nigra pars compacta (SNpc) occur early in the disease process of parkinsonism-related disorders. The increase in iron content, or loss of paramagnetic neuromelanin-iron complexes containing neurons in the nigrosome-1 (the caudal portion of the SNpc), has been explored as a possible biomarker and target in parkinsonian disorders [122]. These alterations can be seen on susceptibility-weighted imaging (SWI), also known as the loss of the "swallow tail sign." This sign has been explored in prodromal stages of $\alpha$-synucleopathies such as RBD [123], and has shown good sensitivity and specificity in the differentiation of PD from controls [124]; in the diagnosis of DLB, sensitivity, specificity, and accuracy were $80 \%, 64 \%$, and $73 \%$, respectively, when compared to AD [125]. This sign was not able to distinguish between PD and other Parkinson-Plus syndromes [126], and studies comparing PDD and DLB patients are lacking.

MRI quantitative susceptibility mapping (QSM) is a novel technique that can quantify the magnetic susceptibility value of brain tissue from gradient-echo (GRE) MRI data, and can more precisely measure the iron deposition compared to those using SWI and transverse relaxation rate $\left(\mathrm{R} 2^{*}\right)$ mapping [127]. Some studies have reported abnormal iron deposits in some deep brain nuclei of PD patients, including the red nucleus, caudate nucleus, globus pallidus, putamen, thalamus, and dentate nucleus [127-130], and in the SN [131,132], but the results are not completely consistent. Studies evaluating the correlation between cognitive impairment in PD and the load of iron content [132,133] have identified that QSM increases covary with (1) MoCA scores in the hippocampus and thalamus; (2) poorer visual function and higher dementia risk scores in parietal, frontal, and medial occipital cortices; and (3) higher UPDRS-III scores in the putamen (all $p<0.05$ ) [133]. QSM has also been used in AD [134], showing positive associations between susceptibility and amyloid PET in the pallidum and putamen, but with variable results regarding cortical areas. Overall, these findings suggest that QSM may be useful to track cognitive changes in PD; however, no studies analyzing patients with DLB are available [135]. 


\subsubsection{Functional Magnetic Resonance Imaging}

Resting-state and task-based functional MRI using perfusion or, more typically, by measuring blood-oxygenation-level-dependent (BOLD) signals using $\mathrm{T} 2{ }^{*}$-weighted have identified multiple networks involving motor and non-motor circuits in PD and DLB.

As in the case of other techniques, the majority of studies evaluate changes of fMRI comparing PDD and DLB against controls or AD [120], but comparisons between PDD and DLB are scarce.

The abnormal integrity of the dorsal attention network and the involvement of its aberrant nodes in working-memory tasks and visual attention in PD has been reported [136,137]. Most groups demonstrated relatively preserved default mode network connectivity [138-140], and disturbed frontoparietal networks and disconnection of the occipital brain regions in DLB compared to healthy controls $[139,141]$. Although few studies found correlations between FC results and motor/cognitive outcomes [139,142,143], most studies did not observe any significant correlations with clinical outcomes after correction for multiple testing. Overall, functional connectivity (FC) in DLB compared to healthy controls, PDD, and, in particular, to AD groups, remains inconclusive to date. The few existing studies of fMRI with a small sample size did not find significant differences between PDD and DLB $[95,140,143]$.

\subsection{Nuclear Medicine and Molecular Imaging in Lewy Body Dementias}

Single-photon emission computed tomography (SPECT) and positron emission tomography (PET) are well-recognized tools to assess function, and even to evaluate in vivo brain pathology (e.g., amyloid PET). Novel radiotracers are emerging for the study of other specific protein species, and the role of these nuclear medicine tools ranges from early research to clinical diagnostic applications used in the clinical setting.

Loss of the neurons in SN is extensive and characteristic for PD and DLB, and leads to a substantial reduction in the striatal presynaptic dopaminergic function showed by a reduction on presynaptic dopamine transporter (DAT) or 18F-dopa uptake [144] (see Figure 3A). Reduced DAT uptake in basal ganglia demonstrated by SPECT or PET imaging has shown to be useful in distinguishing DLB from AD, based on sensitivity $(78 \%)$ and specificity (90\%) [145]. Moreover, some studies have evaluated the sensitivity of DAT in distinguishing prodromal stages of Lewy body disorders from $\mathrm{AD}$, with a sensitivity of $54 \%$ and specificity of $89 \%$ [20]. Although an abnormal DAT scan supports the diagnosis of DLB [14], a normal scan does not exclude DLB altogether, including those cases that present with minimal motor symptoms [146], and does not distinguish between PDD and DLB.

Cerebral perfusion SPECT evaluates the metabolic status of brain tissue by quantifying changes in the regional cerebral blood flow. Occipital hypoperfusion is frequently observed in DLB; however, it was unable to differentiate PDD cases from DLB, revealing similar perfusion profiles in some studies [147]. Occipital hypometabolism combined with a less prominent metabolic decrease in the medial temporal lobe using F-18 fluoro-deoxy-glucose (FDG) PET may be useful in differentiating DLB and PDD from AD [148]. Moreover, the relatively preserved metabolism in the posterior cingulate cortex in DLB, also known as the "cingulate island" sign, achieved the highest sensitivity (100\%) in differentiating DLB from $\mathrm{AD}$, and is also included as a supportive biomarker in the diagnostic criteria of DLB [14] (see Figure 3B). A study directly comparing the accuracy of FDG-PET with SPECT perfusion found that the cingulate island sign was only present with FDG-PET imaging in DLB, but not with SPECT [149]. Patients with PDD showed large areas (occipitoparietal > frontal) of coincidental hypometabolism and atrophy, and the hypometabolism in PD appears to predate and is replaced by atrophy, in a progressive manner as the cognitive state worsens [150]. PDD and DLB often show similar patterns, but a more prominent hypometabolism in the anterior cingulate cortex may distinguish DLB from PDD [148]. The evaluation of the posterior cingulate cortex in PDD has not received attention compared to DLB, in which the preserved metabolism of this area (the cingulate island) has a high sensitivity and specificity in the differential diagnosis from AD [151,152]. 


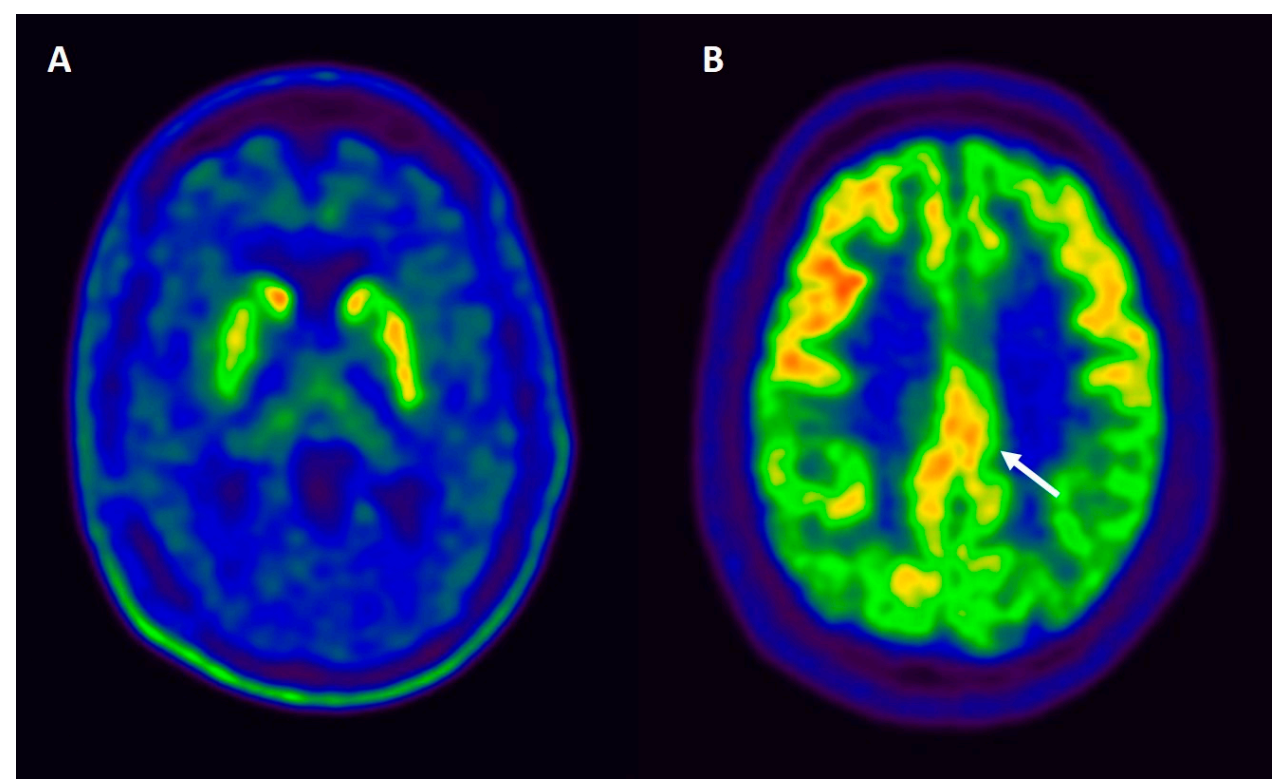

Figure 3. (A) Axial ${ }^{18}$ F-Dopa PET image of a patient with dementia with Lewy bodies. The image shows a moderate decrease of bilateral striatal activity (dopaminergic denervation), more pronounced in the right putamen. (B) FDG-PET findings in a patient with dementia with Lewy bodies. Axial FDG-PET image demonstrates the cingulate island sign (indicated with an arrow), which reflects preservation of posterior cingulate metabolism relative to cuneus and precuneus.

Abnormal cardiac uptake of ${ }^{123} \mathrm{I}$-metaiodobenzylguanidine $\left({ }^{123} \mathrm{I}-\mathrm{MIBG}\right)$ is a diagnostic marker of LBD [153]. Prior findings suggest that cardiac sympathetic function in DLB is severely impaired even in the early disease stage, with the uptake of $\left[{ }^{123}\right.$ I]MIBG being significantly lower than that in patients with PD without dementia [154] (see Figure 4). ${ }^{123}$ I-MIBG scintigraphy is useful to distinguish PD and DLB from other diseases [155], and to discriminate between DLB and AD [21,156] and other parkinsonian disorders [157]. However, specific data comparing DLB and PDD are not available and ${ }^{123}$ I-MIBG imaging is unlikely to differentiate PDD from DLB $[39,158]$. Given its diagnostic accuracy in differentiating DLB from AD, MIBG scintigraphy has been included as an indicative biomarker in the current DLB diagnostic criteria [14]. However, false positive MIBG scintigraphy results due to age, medications, and comorbidities such as diabetes or thyroid dysfunction may limit its use as a routine clinical technique [159].

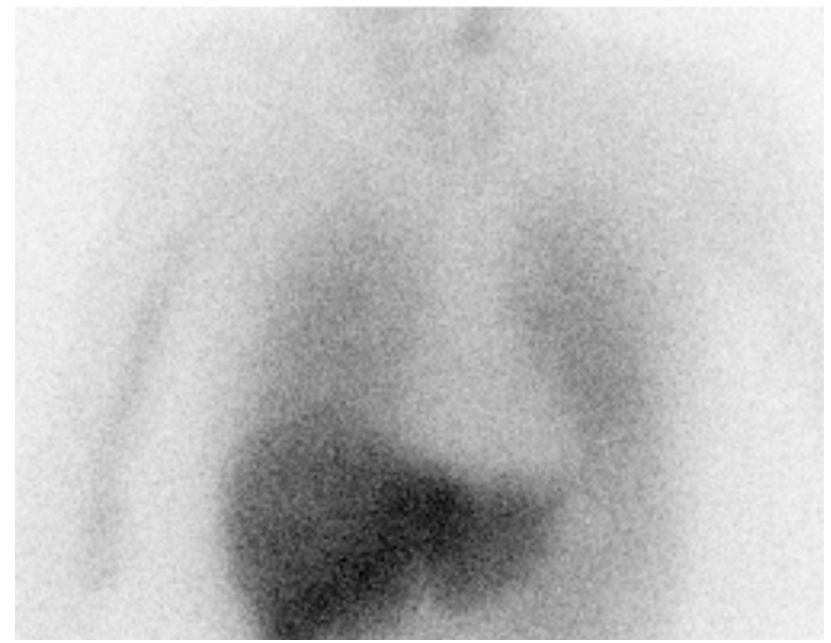

Figure 4. ${ }^{123}$ I-MIBG myocardial scintigraphy image taken $3 \mathrm{~h}$ after injection. The image shows reduced uptake on ${ }^{123}$ I-MIBG in the heart, indicative of dysfunction in the postganglionic sympathetic cardiac innervation. 
Finally, PET scans visualizing the deposition of different proteins in the brain (e.g., PET amyloid quantifying $A \beta$ deposition) have been used to evaluate correlations between cognitive impairment in PDD and DLB [160,161].

The apparent gradient of increasing amyloid pathology visualized on PET can be conceptualized as PD < PD-MCI < PDD < DLB [160]. Studies in PDD and DLB have shown higher rates of amyloid-positive scans than in a normal population [160] and are most consistently associated with worse global cognition in LBD [80,160-164], which matches with the findings of pathology studies $[67,74,165]$. When analyzing prodromal stages of LBD, a recent study found that about one-third of the patients had positive amyloid scans and signs of neuronal dysfunction (measured by hypoperfusion in SPECT scans) early in the disease [166]; this group was older and had worse cognition than the amyloidnegative group. The positivity of $\mathrm{A} \beta$ in MCI-LBD was lower than the ratio reported in probable DLB, which could be due to different stages of brain $A \beta$ accumulation over time in patients with probable DLB. This was shown in the longitudinal study of Nedelska et al. (2019) [167], where probable DLB patients with higher baseline and changes in $A \beta$ measured by standardized uptake value ratios (SUVRs) were associated with more rapid clinical and cognitive decline over time.

PET using tracers to bind tau protein remains a research tool. The burden of cerebral neurofibrillary tangles, in addition to $\alpha$-syn and $\mathrm{A} \beta$ pathology, contributes to the motor and cognitive decline in LBD [66,168-170]. Tau-PET uptake has been observed in patients with PDD and DLB compared to healthy controls [171], and a greater tau uptake in the inferior and lateral temporal gyri and precuneus of DLB and PD-MCI was found compared to PD without cognitive impairment and controls [162]. Although the correlation found between $A \beta$ and tau uptake in the posterior temporoparietal and occipital cortex suggest that DLB patients are associated with AD-related pathology [172], a significant tau burden was present despite minimal amyloid in a small DLB group, suggesting that extensive tauopathy is possible without amyloid deposition in LBD. However, longitudinal studies with bigger samples are needed to clarify the temporal relationship between increased tau uptake and amyloid deposition in DLB [171,172].

Finally, some potentially labeled radiotracers binding $\alpha$-syn and neuroinflammation changes in the brain have been studied in recent years, but their use is still under investigation.

There are many challenges in the development of an $\alpha$-syn tracer, including the low concentrations of the protein compared to $A \beta$, predominant intracellular location of $\alpha$-syn, and off-target binding [173]. Several radiolabeled tracers for $\alpha$-synucleinopathy imaging have been explored $[173,174]$. However, studies evaluating these tracers failed to show accurate binding of $\alpha$-syn aggregates in PDD and DLB [175], and more research is needed to evaluate new tracers with higher affinity binding [176].

Neuroinflammation has also been studied in vivo using PET imaging to evaluate microglial activation (as the innate immune response to invading pathogens) in both PDD and DLB [177]. One widely used PET ligand for imaging neuroinflammation is ${ }^{11}$ C-PK11195, which binds to the translocator protein (TSPO), located on the outer mitochondrial membrane in microglia, and has been evaluated in LBD [178-184]. Compared to controls, increased ${ }^{11}$ C-PK11195 binding in PDD and PD without dementia $[182,183]$ and DLB $[177,179]$ has been observed. Moreover, a significant inverse correlation between levels of microglia activation and glucose metabolism in temporoparietal regions was found in a small sample of PDD and AD, suggesting a deleterious effect of microglia on neuronal function in these dementias [182]. However, there is high variability in the results of clinical studies in PD, which may be due to differences in the evaluated cohorts, the methods of analysis [181], and very small samples [179]. 


\subsection{Molecular Biomarkers in Fluids in Lewy Body Dementias}

\subsubsection{Cerebrospinal Fluid}

Different proteins have been investigated as biomarkers for cognitive decline in dementing disorders, namely, cerebrospinal fluid (CSF) $A \beta-42$ protein $\left(A \beta_{42}\right)$, total tau (t-tau), and p-tau, which are well established in the diagnosis of AD [185]. Low CSF A $\beta_{42}$ levels have been shown to be related to the development of cognitive impairment in PD and DLB [98,109,186-189]. Steenoven et al. (2016) [190] compared AD CSF biomarkers $\left(\mathrm{A} \beta_{42}, \mathrm{t}\right.$-tau, and $\mathrm{p}$-tau) in PD without dementia, PDD, and DLB. Authors found that a large proportion of DLB patients had abnormal values (AD characteristic pattern), whereas in PD without dementia it was uncommon to find these abnormalities and PDD patients had values between the two. Different profiles of CSF A $\beta$ reduction have been described in DLB and $A D$, with $A D$ showing an isolated drop in $A \beta_{42}$, whereas DLB exhibited reductions in $A \beta_{38}, A \beta_{40}$, and $A \beta_{42}$ [191]. An oxidized $\alpha$-helical form of $A \beta_{40}$ peptide was found to be significantly increased in patients with DLB in comparison to PDD, with a sensitivity of $81 \%$ and specificity of $71 \%$ for discriminating among DLB and PDD [192].

CSF levels of total $\alpha$-syn have been found to be lower in DLB and PD compared to controls and AD [193-197]. Real-Time Quaking-Induced Conversion (RT-QuIC) is an ultrasensitive technique able to detect $\alpha$-syn seeding activity across the spectrum of LBD with high sensitivity (95.3\%) and specificity [198] in distinguishing $\alpha$-synucleinopathies from non- $\alpha$ synucleinopathies (including patients with mixed pathology, e.g., AD and DLB) [199].

Longitudinal changes in CSF $\alpha$-syn were also examined in PD cohorts: two studies showed increasing CSF levels over time [193,200], one reported a decrease [201], and another more recent study showed no longitudinal effects [202]. The study of Mollenhauer et al. (2019) [203] showed that CSF $\alpha$-syn decreases early in the disease, preceding motor PD, but does not correlate with progression. Therefore, additional biomarkers or their combination (e.g., ratio of p-tau / $\alpha$-syn and p-tau / Aß1-42+ $\alpha$-syn in PD) have been proposed [204]. Considering the different species of $\alpha$-syn, CSF levels of oligomeric $\alpha$-syn were higher in DLB and PD compared with AD and controls [205], and oligomeric and phosphorylated $\alpha$-syn were also increased in PD compared with controls [206]. Moreover, one study showed that CSF $\alpha$-syn improved the differential diagnosis between AD and LBD at prodromal stages [207], but overall $\alpha$-syn in CSF does not appear to help in the differential diagnosis of PDD and DLB [208]. The combination of CSF $\alpha$-syn with other biomarkers and symptoms might provide more information; however, this remains a matter of research [197].

\subsubsection{Other Biological Fluid Biomarkers}

$\alpha$-syn has been analyzed in multiple peripheral tissues, such as saliva and plasma, using diverse techniques such as enzyme-linked immunosorbent assay, Western blot, mass spectrometry, or Luminex@ assay [209]. Oligomeric $\alpha$-syn has been also visualized in the serum and red blood cells of PD patients [210]. RT-QuIC assays have been also performed on other easily obtainable tissues, such as the olfactory mucosa, in patients with DLB [211] and with isolated RBD (as an early-stage $\alpha$-synucleinopathy) [212], showing a diagnostic accuracy for the clinical diagnoses of DLB of $86.4 \%$ for the olfactory mucosa and $93.8 \%$ for CSF. These results suggest that nasal swabbing might be considered a first-line screening procedure in patients with suspected DLB, followed by CSF analysis in case of incongruent result with the initial clinical diagnosis [212]. Thus, the development of new techniques allowing the measurement of these biomarkers with less invasive procedures are among the most promising diagnostic approaches.

Another potential biomarker that has been examined in CSF and plasma is the neurofilament light chain protein (NfL) [213]. NfL is a biomarker of axonal damage and its levels have been measured in different neurodegenerative disorders [214]. Plasmatic levels of NfL are higher in PDD than in PD with preserved cognition [215]. In addition, plasmatic levels of NfL showed a good correlation with cognitive function, but not with motor function in 49 PD patients [215]. NfL was found to be elevated in DLB, but no significant differences 
have been observed in comparison with other dementias. Therefore, NfLs appear to provide only a general hint of neuronal and axonal degeneration, without a differential value for separating DLB from other disorders $[213,216]$.

The role of neuroinflammation in the pathogenesis of neurodegenerative disorders is increasingly being recognized. Inflammation may be involved early in the cognitive decline of patients with MCI due to AD and DLB, and possibly less prominent in PD, as noted per a study measuring different cytokines, such as interferon gamma, interleukin (IL)-10, IL-12p70, IL-13, IL-1beta, IL-2, IL-4, IL-6, IL-8, tumor necrosis factor alpha, and high-sensitivity C-reactive protein [217]. Other studies have found similar results, showing an increase in inflammatory factors in patients with possible and probable AD and DLB in the prodromal stages $[177,218,219]$, although these factors probably do not help in distinguishing subtypes of MCI (due to AD vs. DLB or PD) [218].

Among other fluid biomarkers, vitamin D, lipids, and neurotrophic factors have been explored in LBD and in dementia overall [109,220-225], in addition to synaptic and cytosolic proteins, circulating mitochondrial DNA, and fatty acid binding protein $3[109,186,226,227]$. For instance, low uric acid has been shown to be possibly involved in the occurrence of LBD and cognitive decline [228,229]. However, the results of these studies are not robust and need further investigation in larger samples.

\subsection{Neurophysiological Biomarkers}

Evidence is building to support quantitative electroencephalogram (EEG) as a DLB supportive biomarker, characterized by specific abnormalities in posterior derivations with prominent posterior slow-wave EEG activity and periodic fluctuations in the prealpha/theta range [14,230-233]. This specific EEG pattern is included as a supportive biomarker of DLB [14], and also correlates positively with the severity of clinically observed cognitive fluctuations [232], and may be seen at the MCI stage [234].

Sleep disturbance is common in dementia and changes in the architecture of sleep, especially those seen in REM, have been related to the incidence of dementia [235]. The confirmation of REM sleep without atonia using a polysomnography, in conjunction with one or more clinical features, is sufficient for the diagnosis of DLB. RBD is included as a core clinical feature because it occurs frequently in autopsy-confirmed cases compared with non-DLB (76\% vs. $4 \%$ ) [236].

Table 3. Summary of the overlap and dissimilarities in the biomarker findings of PDD, DLB, and AD.

\begin{tabular}{|c|c|c|}
\hline Biomarkers & PDD versus DLB & PDD/DLB versus AD \\
\hline MRI & $\begin{array}{l}\text { VBM: Diffuse cortical atrophy in both PDD and } \\
\text { DLB; gray matter reductions in the temporal, } \\
\text { parietal and occipital lobes in DLB [93,102]. } \\
\text { DTI: controversial, corticostriatal disruption in } \\
\text { PDD is more frontal and in DLB more posterior } \\
\text { (parietal and occipital) }[39,102,120] . \\
\text { SWI: Nigrosome } 1 \text { "swallow tail sign" } \\
\text { differentiates PD from controls [124]. No studies } \\
\text { comparing DLB from PDD. } \\
\text { QSM: Higher iron load in hippocampus, thalamus, } \\
\text { parietal, frontal, and occipital cortices correlate } \\
\text { with cognition in PD [127-133]. No studies in DLB. } \\
\text { fMRI: No conclusive differences between PDD } \\
\text { and DLB [95,139,140]. }\end{array}$ & $\begin{array}{l}\text { VBM: Insular cortical thinning may differentiate } \\
\text { DBL from AD [99,100]. Preserved hippocampal } \\
\text { volumes in DBL differentiate from AD [14]. } \\
\text { DTI: Posterior regions affected in DLB more than } \\
\text { AD [116]. } \\
\text { SWI: Nigrosome } 1 \text { “swallow tail sign” } \\
\text { differentiates DLB from AD with sensitivity } \\
\text { (80\%) [125]. } \\
\text { QSM: Positive associations between susceptibility } \\
\text { and amyloid PET in the pallidum and putamen of } \\
\text { AD [134]. No studies in DLB. } \\
\text { fMRI: No major differences between DLB and } \\
\text { AD groups [138]. }\end{array}$ \\
\hline PET and SPECT & $\begin{array}{l}\text { DAT: Reduced dopamine transporter uptake in } \\
\text { PD and DLB. } \\
\text { SPECT perfusion and FDG-PET: } \\
\text { Similar perfusion profiles in PDD and DLB, with } \\
\text { posterior hypoperfusion and hypometabolism } \\
\text { (inferior parietal and occipital cortices) }[149,152] \text {. }\end{array}$ & $\begin{array}{l}\text { DAT: Reduced striatal DAT uptake in DLB, useful } \\
\text { in the differential diagnosis from AD, sensitivity } \\
(78 \%) \text {, and specificity (90\%) [145]. } \\
\text { SPECT perfusion and FDG-PET: Greater } \\
\text { hypoperfusion in the parietooccipital cortex in } \\
\text { DLB and PDD compared to AD [147]. } \\
\text { Occipital hypometabolism combined with a less }\end{array}$ \\
\hline
\end{tabular}


Table 3. Cont

\begin{tabular}{|c|c|c|}
\hline Biomarkers & PDD versus DLB & PDD/DLB versus AD \\
\hline & $\begin{array}{l}\text { More prominent hypometabolism in the anterior } \\
\text { cingulate in DLB than PDD [148]. }\end{array}$ & $\begin{array}{l}\text { prominent metabolic decline in the medial } \\
\text { temporal lobe in DBL vs. AD [148]. The "cingulate } \\
\text { island" sign has high sensitivity (100\%) in } \\
\text { differentiating DLB from AD [14]. }\end{array}$ \\
\hline PET amyloid and tau & $\begin{array}{l}\text { amyloid: Increasing amyloid pathology PD < } \\
\text { PD-MCI < PDD < DLB. Positive amyloid PET is } \\
\text { associated with worse global cognition in } \\
\text { LBD [161-163,172]. } \\
\text { tau: Under investigation, no conclusive data. }\end{array}$ & $\begin{array}{l}\text { amyloid: Positive amyloid PET indicative of } \\
\text { amyloid pathology (AD or co-pathology with LBD) } \\
\text { tau: Under investigation, no conclusive data. }\end{array}$ \\
\hline $\begin{array}{l}{\left[{ }^{123} \mathrm{I}\right] \mathrm{MIBG}} \\
\text { Scintigraphy }\end{array}$ & $\begin{array}{l}\text { Lower uptake in DLB than those with PDD [154], } \\
\text { but the latest can also be positive. }\end{array}$ & $\begin{array}{l}\text { Would help to differentiate AD from } \\
\text { LBD }[21,156,157] \text {. }\end{array}$ \\
\hline $\begin{array}{l}\text { Molecular fluid } \\
\text { biomarkers }\end{array}$ & $\begin{array}{c}\text { CSF: } \\
\text { (1) Low CSF A } \beta_{42} \text { levels predict cognitive } \\
\text { impairment in PD and DLB [98,109,186-189]. } \\
\text { Oxidized } \alpha \text {-helical form of A } \beta_{1-40} \text { peptide } \\
\text { significantly increased in patients with DLB in } \\
\text { comparison to PDD [191]. } \\
\text { (2) Lower } \alpha \text {-syn in DLB and PD than in } \\
\text { controls [193,196,208]. It may not be useful to } \\
\text { differentiate between PDD and DLB [208]. } \\
\text { (3) Other biomarkers: Inflammatory factors may } \\
\text { increase in PDD and DLB but may not differentiate } \\
\text { them [218]. NfL was also elevated in DLB, but no } \\
\text { significant differences compared to PDD [213,216]. }\end{array}$ & $\begin{array}{l}\text { CSF: } \\
\text { (1) AD pattern (low A } \beta_{42} \text {, high t-tau and p-tau): } \\
\text { AD > DLB > PDD > PD [191]. } \\
\text { (2) } \alpha \text { - oligomeric } \alpha \text {-syn higher in DLB and PDD } \\
\text { compared with AD and controls [195,197,205], } \\
\text { also at prodromal stages [207] } \\
\text { (3) Other biomarkers: unspecific elevation of NfL } \\
\text { levels in DLB, which do not distinguish from other } \\
\text { dementias [213]. }\end{array}$ \\
\hline $\begin{array}{l}\text { Other potential } \\
\text { biomarkers }\end{array}$ & $\begin{array}{l}\text { Microglia activation: Increased 11C-PK11195 } \\
\text { binding in several regions in PDD and } \\
\text { DLB [178-181], but still under investigation } \\
\text { (no conclusive data). }\end{array}$ & $\begin{array}{c}\text { Microglia activation: Under investigation, } \\
\text { no conclusive data. }\end{array}$ \\
\hline
\end{tabular}

PDD, Parkinson disease dementia; DLB, Dementia with Lewy bodies; VBM, Voxel-based morphometry; DTI, Diffusion Tensor Imaging; SWI, susceptibility-weighted imaging; QSM, quantitative susceptibility mapping; fMRI, functional magnetic resonance imaging; DAT, dopamine transporter; SPECT, single-photon emission computed tomography; PET-FDG, F-18 fluoro-deoxy-glucose positron emission tomography; ( $\left.{ }^{123} \mathrm{I}-\mathrm{MIBG}\right),{ }^{123} \mathrm{I}$-metaiodobenzylguanidine; CSF, cerebrospinal fluid.

\section{Evolution and Prognosis of Lewy Body Dementias}

It is relevant to note that, although the clinical and pathologic features of PDD and DLB may overlap, the presentation and natural course are usually different. This is important to provide the most accurate information regarding the prognosis and evolution of these entities to the patients and caregivers. In patients with DLB, parkinsonian symptoms appear on average two years after estimated dementia onset [237]; this is in contrast to PDD patients, who must have a well-established diagnosis of PD before dementia begins. Motor manifestations are often more severe in PDD than in DLB; however, DLB patients may respond less to medications [159]. In comparison with DLB, PDD patients commonly have greater motor disability and higher medication burden. Once dementia appears in $\mathrm{PD}$, the prognosis is assumed to be poor, although few studies have focused on the rate of cognitive decline or mortality after dementia onset [238]. Patients with PDD are on average younger than patients with other kinds of dementia, but they have more comorbidity and take more medications, which might increase their mortality compared to other populations [238]. Some of the factors that influence mortality are male gender, a higher number of medications, institutionalization, and age [238]. Age has consistently been demonstrated to be an important predictor of both dementia and mortality in LBD [239].

The course of DLB generally shows a more rapid cognitive decline compared to AD or PDD [240], with an average survival time in DLB being 1.60 years shorter than that in AD [241]. In a retrospective cohort of DLB patients [242], authors found that an amnestic cognitive profile conferred a worse outcome. Furthermore, there is an emerg- 
ing consensus for the role of concurrent pathologies (e.g., concomitant AD pathology) accelerating cognitive decline in DLB and PDD [66,67,91,241], and other factors such as neuropsychiatric symptoms (especially aggression and psychosis) have been shown to trigger institutionalization, leading to poorer outcomes [241].

\section{Management of Lewy Body Dementias}

Currently, there are no effective therapies that modify the course of LBD. Thus, treatment of both PDD and LBD is mainly focused in managing the more prominent symptoms of the disease (e.g., motor and neuropsychiatric). The management of PDD and DLB is specifically covered in another chapter of this Special Issue, so we will summarize the main therapeutic strategies used in LBD.

One of the first steps is to assess possible harmful medications that could worsen cognitive or motor symptoms in LBD (e.g., benzodiazepines, opiates, anticholinergic medications, or anti-dopaminergic drugs) $[159,243]$.

Evidence supports the use of cholinesterase inhibitors (ChEIs) to treat cognitive and neuropsychiatric symptoms in LBD [244,245]. Moreover, a meta-analysis and trial sequential analysis showed that both ChEIs and memantine improve clinical global impression; however, only ChEIs enhanced cognitive function [244]. Both donepezil and rivastigmine are recommended ChEIs for DLB [246], whereas rivastigmine is the only cholinesterase inhibitor FDA-approved for use in PDD. The evidence for the third ChEI, galantamine, in LBD is scarce because only open-label trials support its use [244]. Clinical trials of the NDMA receptor antagonist memantine showed that it was well tolerated in patients with both PDD and DLB, but evidence for its efficacy remains mixed [244,246-248]. Therefore, further studies with larger numbers are needed to determine its use as a monotherapy or combined with ChEIs [245].

Regarding the management of motor symptoms in LBD, dopaminergic replacement therapy is used. Dopamine agonists are avoided as they may worsen cognitive and behavioral symptoms, especially in DLB, so low doses of levodopa as a monotherapy is the most common approach in these cases [159]. Motor function appears to improve more in PDD patients (65-70\%) than in those with dementia with Lewy bodies (32-50\%) [247]. However, one in three patients with DLB treated with levodopa will experience psychotic symptoms, which need to be taken into account [249]. A meta-analysis of four doubleblind randomized controlled trials, including PD [250] and DLB patients [251], reported a significant improvement in motor function with zonisamide, an antiepileptic agent, when used as adjunctive treatment to levodopa.

As per the management of neuropsychiatric symptoms in LBD, non-pharmacological approaches are considered to be first-line strategies (e.g., environmental modifications or musical therapy). However, evidence supporting their efficacy is not robust [252]. Non-bothersome hallucinations and delusions may not require pharmacological treatment. However, disturbing psychotic symptoms could require the use of antipsychotics. Although there is not enough evidence to support the use of any particular antipsychotic drug over others, quetiapine appears to have the fewest side effects in patients with LBD, but evidence for its efficacy in patients with PD [253] and those with Lewy body dementia is insufficient $[247,254]$. Quetiapine and clozapine, as the remainder of the atypical antipsychotics, carry the risk of weight gain and metabolic syndrome. Their use is of particular concern in individuals with DLB given the risk of hypersensitivity reactions to neuroleptics (e.g., sudden deterioration in motor symptoms and/or mental status changes, such as confusion or even unresponsiveness) [159].

Pimavanserin is a selective serotonin (5-HT) 2A receptor inverse agonist and the US Food and Drug Administration (FDA) approves it only for PD psychosis. A meta-analysis of 13 randomized placebo-controlled trials in PD including Pimavanserin, clozapine, olanzapine, and quetiapine showed that Pimavanserin was associated with a significant improvement in psychotic symptoms compared to a placebo, without worsening motor function. Clozapine was efficacious in alleviating psychotic symptoms and did not ex- 
acerbate motor function, but quetiapine and olanzapine did not demonstrate significant differences in reducing psychotic symptoms and may aggravate motor function. Therefore, more well-designed trials confirming these results are needed. There is an ongoing clinical trial evaluating the use of Pimavanserin in dementia-related psychosis, also including DLB (NCT03325556).

Among other non-motor symptoms, sleep disturbances are frequently present in LBD. Melatonin has been shown to be safe and well tolerated, and is considered to be the first-line agent for treating RBD in patients with LBD [159]. Additionally, clonazepam is often tried if melatonin is not sufficiently effective [255].

\section{Discussion}

DLB and PDD are clinically and neuropathologically similar entities distinguished based on the timing of dementia and parkinsonism. Overlapping clinical features and supportive biomarker findings in PDD and DLB complicate their differential diagnosis. Diagnosis is mainly determined based on history, examination, and neuropsychological and neuropsychiatric assessment.

Some characteristics of the cognitive profile and behavioral symptoms, such as greater impairment and more rapid decline of executive function in PDD than DLB, or more severe visuospatial deficits and visual hallucinations in DLB than PDD, may differ between these two entities but they are not useful to discriminate between on an individual basis.

The controversy persists regarding whether DLB and PDD represent two distinct nosological entities or whether they exist on a clinicopathological spectrum of the same disorder. Smirnov et al. (2020) [30] showed that even if DLB and PDD may be nearly indistinguishable pathologically, the two may differ cognitively in the progression of the disease (e.g., visuoperceptual and visuoconstructional functions and verbal and visual memory may be worse in DLB), adding to the current debate on whether the conditions should be pooled or treated separately. A shift to a pathologic classification (e.g., LBDdementia or LBD-parkinsonism) has been proposed and could become more relevant if $\alpha$-syn biomarkers are developed.

Different pathological studies have shown that the manner in which $\alpha$-syn is topographically spread (transitional vs. diffuse Lewy body disease) and other synergistic actions ( $\mathrm{A} \beta$ and tau co-pathology) may influence the clinical presentation and therefore the diagnosis received early in the disease process. The clinical differentiation between DLB and PDD is still based on an arbitrary distinction between the time of onset of parkinsonism and cognitive symptoms (the one-year rule). However, due to the recent effort made by investigators in developing updated diagnostic criteria for the prodromal stages in DBL and the ongoing research of reliable biomarkers for identifying patients in the early stages of the disease, these diagnostic criteria may change in the near future.

The clinical diagnosis in prodromal stages should be of the utmost importance because, like in other neurodegenerative disorders, early and proper management of the disease might change the evolution and outcomes of the illness. The identification of novel biomarkers is another area of active research. As we have shown in this article, multiple biomarkers could be used in clinical practice to help clinicians in the diagnosis of LBD. Indeed, supportive and indicative biomarkers are included as part of the diagnostic criteria of DLB, whereas the current clinical criteria for PDD do not include biomarker information.

Numerous other novel biomarkers are in development which might change the landscape of in vivo LBD diagnosis. It is likely that the combination of a variety of techniques will provide more accurate results than when each is used separately. We have proposed an algorithm for the diagnosis workup in PDD and DLB (see Figures 1 and 2), which could be used in clinical settings. Among other approaches, the use of FDG-PET, DAT-scan or ${ }^{18}$ F-Dopa PET, and scintigraphy [123 I]MIBG, can be useful to distinguish LBD from other neurodegenerative processes such as AD. The evaluation of CSF biomarkers might add additional value to the diagnosis process, particularly if new techniques allow us to accurately measure $\alpha$-syn. The focus on $\alpha$-syn pathology has both diagnostic and therapeutic 
implications in the development of disease-modifying treatments. There is a need for a suitable PET radiotracer for imaging of LB pathology, which would represent a valuable tool for that purpose.

The current treatment of LBD remains symptomatic and consists of avoiding medications that may cause or exacerbate symptoms, in addition to other pharmacological and non-pharmacological therapies to alleviate the symptoms of PDD and DLB patients. Clinical trials are ongoing with new molecules that may modify the course of LBD [256] (e.g., ambroxol, NCT02914366, and bosutinib, NCT03888222).

Patient selection approaches for investigational studies focused on cognitive deficits in DLB and PDD may consist of excluding patients without physiological evidence of these diseases, or enriching the mechanism of action or phenotype of interest [257]. In 2019, the Lewy Body Dementia Association (LBDA) launched the Industry Advisory Council to provide a collaborative forum for discussion among LBD experts, pharmaceutical industries, governmental agencies, and the non-profit LBDA to address challenges and opportunities for LBD clinical trials [256]. Refining diagnostic accuracy and continued exploration of the use of clinical and potential research biomarkers is needed to reduce heterogeneity in clinical trials and improve the landscape of DLB.

Author Contributions: Conceptualization, Á.M.-T., M.F.-M., and M.C.R.-O.; methodology, Á.M.-T., M.F.-M., and M.C.R.-O.; validation, M.F.-M. and M.C.R.-O.; writing-original draft preparation Á.M.T.; writing—review and editing, Á.M.-T., M.F.-M., and M.C.R.-O.; visualization, Á.M.-T., M.F.-M., and M.C.R.-O.; supervision, M.F.-M. and M.C.R.-O.; project administration Á.M.-T., M.F.-M., and M.C.R.-O. All authors have read and agreed to the published version of the manuscript.

Funding: This research received no external funding.

Institutional Review Board Statement: Not applicable.

Informed Consent Statement: Not applicable.

Data Availability Statement: Not applicable.

Acknowledgments: This research did not receive any specific grant from funding agencies in the public, commercial, or not-for-profit sectors. Authors thank E.D. Guillen and J. Arbizu, from the department of Nuclear Medicine at Clínica Universidad de Navarra, for their contribution to the work providing the Nuclear Medicine images.

Conflicts of Interest: Á.M.-T. and M.F.-M. report no conflict of interest. M.C.R.-O. received financial support for her research from national and local government institutions in Spain (Carlos III Institute of Health, Basque Country Government, Diputacion Foral Guipuzcoa, and CIBERNED). M.C.R.-O. received honoraria from Insightec, Zambon, Bial, and Boston Scientific for lectures, travel, and accommodation to attend scientific meetings. BCBL acknowledges support from the Basque Government through the BERC 2018-2021 program.

\section{References}

1. Harding, A.J.; Halliday, G.M. Cortical Lewy body pathology in the diagnosis of dementia. Acta Neuropathol. 2001, 102, 355-363. [CrossRef] [PubMed]

2. Klein, J.C.; Eggers, C.; Kalbe, E.; Weisenbach, S.; Hohmann, C.; Vollmar, S.; Baudrexel, S.; Diederich, N.J.; Heiss, W.D.; Hilker, R. Neurotransmitter changes in dementia with Lewy bodies and Parkinson disease dementia in vivo. Neurology $2010,74,885-892$. [CrossRef] [PubMed]

3. Zaccai, J.; McCracken, C.; Brayne, C. A systematic review of prevalence and incidence studies of dementia with Lewy bodies. Age Ageing 2005, 34, 561-566. [CrossRef] [PubMed]

4. Hogan, D.B.; Fiest, K.M.; Roberts, J.I.; Maxwell, C.J.; Dykeman, J.; Pringsheim, T.; Steeves, T.; Smith, E.E.; Pearson, D.; Jetté, N. The prevalence and incidence of dementia with lewy bodies: A systematic review. Can. J. Neurol. Sci. 2016, 43, S83-S95. [CrossRef]

5. Pfeiffer, R.F. Non-motor symptoms in Parkinson's disease. Park. Relat. Disord. 2016, 22, S119-S122. [CrossRef]

6. Rodriguez-Oroz, M.C.; Jahanshahi, M.; Krack, P.; Litvan, I.; Macias, R.; Bezard, E.; Obeso, J.A. Initial clinical manifestations of Parkinson's disease: Features and pathophysiological mechanisms. Lancet Neurol. 2009, 8, 1128-1139. [CrossRef]

7. Litvan, I.; Goldman, J.G.; Tröster, A.I.; Schmand, B.A.; Weintraub, D.; Petersen, R.C.; Mollenhauer, B.; Adler, C.H.; Marder, K.; Williams-Gray, C.H.; et al. Diagnostic criteria for mild cognitive impairment in Parkinson's disease: Movement Disorder Society Task Force guidelines. Mov. Disord. 2012, 27, 349-356. [CrossRef] 
8. Goldman, J.G.; Sieg, E. Cognitive impairment and dementia in Parkinson disease. Clin. Geriatr. Med. 2020, 36, 365-377. [CrossRef]

9. Nicoletti, A.; Luca, A.; Baschi, R.; Cicero, C.E.; Mostile, G.; Davì, M.; Pilati, L.; Restivo, V.; Zappia, M.; Monastero, R. Incidence of mild cognitive impairment and dementia in Parkinson's disease: The Parkinson's disease cognitive impairment study. Front. Aging Neurosci. 2019, 10, 1-12. [CrossRef]

10. Janvin, C.C.; Larsen, J.P.; Aarsland, D.; Hugdahl, K. Subtypes of mild cognitive impairment in Parkinson's disease: Progression to dementia. Mov. Disord. 2006, 21, 1343-1349. [CrossRef]

11. Gasca-Salas, C.; Estanga, A.; Clavero, P.; Aguilar-Palacio, I.; González-Redondo, R.; Obeso, J.A.; Rodriguez-Oroz, M.C. Longitudinal assessment of the pattern of cognitive decline in non-demented patients with advanced Parkinson's disease. J. Parkinson's Dis. 2014, 4, 677-686. [CrossRef]

12. Litvan, I.; Aarsland, D.; Adler, C.H.; Goldman, J.G.; Kulisevsky, J.; Mollenhauer, B.; Rodriguez-Oroz, M.C.; Tröster, A.I.; Weintraub, D. MDS task force on mild cognitive impairment in Parkinson's disease: Critical review of PD-MCI. Mov. Disord. 2011, 26, 1814-1824. [CrossRef]

13. Hely, M.A.; Reid, W.G.J.; Adena, M.A.; Halliday, G.M.; Morris, J.G.L. The Sydney Multicenter Study of Parkinson's disease: The inevitability of dementia at 20 years. Mov. Disord. 2008, 23, 837-844. [CrossRef]

14. Mckeith, I.G.; Sci, M.; Boeve, B.F.; Dickson, D.W.; Halliday, G.; Taylor, J.-P.; Psych, M.; Weintraub, D.; Aarsland, D.; Galvin, J.; et al. Diagnosis and management of dementia with Lewy bodies Fourth consensus report of the DLB Consortium. Neurology 2017, 89, 88-100. [CrossRef] [PubMed]

15. Emre, M.; Aarsland, D.; Brown, R.; Burn, D.J.; Duyckaerts, C.; Mizuno, Y.; Broe, G.A.; Cummings, J.; Dickson, D.W.; Gauthier, S.; et al. Clinical diagnostic criteria for dementia associated with Parkinson's disease. Mov. Disord. 2007, 22, 1689-1707. [CrossRef]

16. McKeith, I.G.; Dickson, D.W.; Lowe, J.; Emre, M.; O’Brien, J.T.; Feldman, H.; Cummings, J.; Duda, J.E.; Lippa, C.; Perry, E.K.; et al. Diagnosis and management of dementia with Lewy bodies: Third report of the DLB consortium. Neurology 2005, 65, 1863-1872. [CrossRef]

17. Gomperts, S.N. Lewy body dementias. Contin. Lifelong Learn. Neurol. 2016, 22, 435-463. [CrossRef]

18. Mckeith, I.G.; Sci, M.; Ferman, T.J.; Thomas, A.J.; Blanc, F.; Boeve, B.F.; Fujishiro, H.; Kantarci, K.; Muscio, C.; O’brien, J.T.; et al. Research criteria for the diagnosis of prodromal dementia with Lewy bodies. Neurology 2020, 94, 743-755. [CrossRef]

19. Galvin, J.E. Improving the clinical detection of Lewy body dementia with the Lewy body composite risk score. Alzheimer's Dement. Diagn. Assess. Dis. Monit. 2015, 1, 316-324. [CrossRef]

20. Thomas, A.J.; Donaghy, P.; Roberts, G.; Colloby, S.J.; Barnett, N.A.; Petrides, G.; Lloyd, J.; Olsen, K.; Taylor, J.P.; McKeith, I.; et al. Diagnostic accuracy of dopaminergic imaging in prodromal dementia with Lewy bodies. Psychol. Med. 2019, 49, 396-402. [CrossRef] [PubMed]

21. Yoshita, M.; Taki, J.; Yamada, M. A clinical role for [123I]MIBG myocardial scintigraphy in the distinction between dementia of the Alzheimer's-type and dementia with Lewy bodies. J. Neurol. Neurosurg. Psychiatry 2001, 71, 583-588. [CrossRef] [PubMed]

22. Williams-Gray, C.H.; Mason, S.L.; Evans, J.R.; Foltynie, T.; Brayne, C.; Robbins, T.W.; Barker, R.A. The CamPaIGN study of Parkinson's disease: 10-year outlook in an incident population-based cohort. J. Neurol. Neurosurg. Psychiatry 2013, 84, 1258-1264. [CrossRef]

23. Nobili, F.; Morbelli, S.; Arnaldi, D.; Ferrara, M.; Campus, C.; Brugnolo, A.; Mazzei, D.; Mehrdad, N.; Sambuceti, G.; Rodriguez, G. Radionuclide brain imaging correlates of cognitive impairment in Parkinson's disease (PD). J. Neurol. Sci. 2011, $310,31-35$. [CrossRef] [PubMed]

24. Shimada, H.; Hirano, S.; Shinotoh, H.; Aotsuka, A.; Sato, K.; Tanaka, N.; Ota, T.; Asahina, M.; Fukushi, K.; Kuwabara, S.; et al. Mapping of brain acetylcholinesterase alterations in Lewy body disease by PET. Neurology 2009, 73, 273-278. [CrossRef]

25. Bohnen, N.I.; Kaufer, D.I.; Ivanco, L.S.; Lopresti, B.; Koeppe, R.A.; Davis, J.G.; Mathis, C.A.; Moore, R.Y.; DeKosky, S.T. Cortical cholinergic function is more severely affected in Parkinsonian dementia than in Alzheimer disease: An in vivo positron emission tomographic study. Arch. Neurol. 2003, 60, 1745-1748. [CrossRef]

26. Litvan, I.; Mohr, E.; Williams, J.; Gomez, C.; Chase, T.N. Differential memory and executive functions in demented patients with Parkinson's and Alzheimer's disease. J. Neurol. Neurosurg. Psychiatry 1991, 54, 25-29. [CrossRef]

27. Ferman, T.J.; Smith, G.E.; Boeve, B.F.; Graff-Radford, N.R.; Lucas, J.A.; Knopman, D.S.; Petersen, R.C.; Ivnik, R.J.; Wszolek, Z.; Uitti, R.; et al. Neuropsychological differentiation of dementia with Lewy bodies from normal aging and Alzheimer's disease. Clin. Neuropsychol. 2006, 20, 623-636. [CrossRef]

28. Mosimann, U.P.; Mather, G.; Wesnes, K.A.; O’Brien, J.T.; Burn, D.J.; McKeith, I.G. Visual perception in Parkinson disease dementia and dementia with Lewy bodies. Neurology 2004, 63, 2091-2096. [CrossRef]

29. Robertson, A.D.; Messner, M.A.; Shirzadi, Z.; Kleiner-Fisman, G.; Lee, J.; Hopyan, J.; Lang, A.E.; Black, S.E.; MacIntosh, B.J.; Masellis, M. Orthostatic hypotension, cerebral hypoperfusion, and visuospatial deficits in Lewy body disorders. Park. Relat. Disord. 2016, 22, 80-86. [CrossRef]

30. Smirnov, D.S.; Galasko, D.; Edland, S.D.; Filoteo, J.V.; Hansen, L.A.; Salmon, D.P. Cognitive decline profiles differ in Parkinson disease dementia and dementia with Lewy bodies. Neurology 2020, 94, e2076-e2087. [CrossRef]

31. Whittington, C.J.; Podd, J.; Kan, M.M. Recognition memory impairment in Parkinson's disease: Power and meta-analyses. Neuropsychology 2000, 14, 233-246. [CrossRef] [PubMed] 
32. Filoteo, J.V.; Salmon, D.P.; Schiehser, D.M.; Kane, A.E.; Hamilton, J.M.; Rilling, L.M.; Lucas, J.A.; Zizak, V.; Galasko, D.R. Verbal learning and memory in patients with dementia with Lewy bodies or Parkinson's disease with dementia. J. Clin. Exp. Neuropsychol. 2009, 31, 823-834. [CrossRef] [PubMed]

33. O'Dowd, S.; Schumacher, J.; Burn, D.J.; Bonanni, L.; Onofrj, M.; Thomas, A.; Taylor, J.P. Fluctuating cognition in the Lewy body dementias. Brain 2019, 142, 3338-3350. [CrossRef] [PubMed]

34. Ballard, C.G.; Aarsland, D.; McKeith, I.; O’Brien, J.; Gray, A.; Cormaak, F.; Burn, D.; Cassidy, T.; Starfeldt, R.; Larsen, J.P.; et al. Fluctuations in attention: PD dementia vs DLB with parkinsonism. Neurology 2002, 59, 1714-1720. [CrossRef]

35. Lee, D.R.; Taylor, J.P.; Thomas, A.J. Assessment of cognitive fluctuation in dementia: A systematic review of the literature. Int. J. Geriatr. Psychiatry 2012, 27, 989-998. [CrossRef]

36. Van Dyk, K.; Towns, S.; Tatarina, O.; Yeung, P.; Dorrejo, J.; Zahodne, L.B.; Stern, Y. Assessing fluctuating cognition in dementia diagnosis. Am. J. Alzheimer's Dis. Other Dement. 2016, 31, 137-143. [CrossRef]

37. Dorrejo, J.; Zahodne, L.B.; Stern, Y. Interrater reliability of the clinician assessment of fluctuation. Am. J. Alzheimer's Dis. Other Dement. 2016, 31, 137-143. [CrossRef]

38. Fields, J.A. Cognitive and neuropsychiatric features in Parkinson's and Lewy body dementias. Arch. Clin. Neuropsychol. 2017, 32, 786-801. [CrossRef]

39. Jellinger, K.A.; Korczyn, A.D. Are dementia with Lewy bodies and Parkinson's disease dementia the same disease? BMC Med. 2018, 16, 34. [CrossRef]

40. Lenka, A.; Pagonabarraga, J.; Pal, P.K.; Bejr-Kasem, H.; Kulisvesky, J. Minor hallucinations in Parkinson disease: A subtle symptom with major clinical implications. Neurology 2019, 93, 259-266. [CrossRef]

41. Martínez-Horta, S.; Riba, J.; de Bobadilla, R.F.; Pagonabarraga, J.; Pascual-Sedano, B.; Antonijoan, R.M.; Romero, S.; Mañanas, M.À.; García-Sanchez, C.; Kulisevsky, J. Apathy in parkinson's disease: Neurophysiological evidence of impaired incentive processing. J. Neurosci. 2014, 34, 5918-5926. [CrossRef]

42. Weintraub, D.; Mamikonyan, E. The Neuropsychiatry of Parkinson disease: A perfect storm. Am. J. Geriatr. Psychiatry 2019, 27, 998-1018. [CrossRef]

43. Aarsland, D.; Ballard, C.; Larsen, J.P.; McKeith, I. A comparative study of psychiatric symptoms in dementia with Lewy bodies and Parkinson's disease with and without dementia. Int. J. Geriatr. Psychiatry 2001, 16, 528-536. [CrossRef]

44. Marsh, L. Depression and Parkinson's disease: Current knowledge. Curr. Neurol. Neurosci. Rep. 2013, 13, 409. [CrossRef]

45. Patterson, L.; Rushton, S.P.; Attems, J.; Thomas, A.J.; Morris, C.M. Degeneration of dopaminergic circuitry influences depressive symptoms in Lewy body disorders. Brain Pathol. 2019, 29, 544-557. [CrossRef]

46. Ishihara, L.; Brayne, C. A systematic review of depression and mental illness preceding Parkinson's disease. Acta Neurol. Scand. 2006, 113, 211-220. [CrossRef]

47. McKeith, I.; Cummings, J. Behavioural changes and psychological symptoms in dementia disorders. Lancet Neurol. 2005, 4, 735-742. [CrossRef]

48. Kuring, J.K.; Mathias, J.L.; Ward, L. Prevalence of depression, anxiety and PTSD in people with dementia: A systematic review and meta-analysis. Neuropsychol. Rev. 2018, 28, 393-416. [CrossRef]

49. Fritze, F.; Ehrt, U.; Hortobagyi, T.; Ballard, C.; Aarsland, D. Depressive symptoms in Alzheimer's disease and Lewy body dementia: A one-year follow-up study. Dement. Geriatr. Cogn. Disord. 2011, 32, 143-149. [CrossRef]

50. Aarsland, D.; Brønnick, K.; Ehrt, U.; De Deyn, P.P.; Tekin, S.; Emre, M.; Cummings, J.L. Neuropsychiatric symptoms in patients with Parkinson's disease and dementia: Frequency, profile and associated care giver stress. J. Neurol. Neurosurg. Psychiatry 2007, 78, 36-42. [CrossRef]

51. Borroni, B.; Agosti, C.; Padovani, A. Behavioral and psychological symptoms in dementia with Lewy-bodies (DLB): Frequency and relationship with disease severity and motor impairment. Arch. Gerontol. Geriatr. 2008, 46, 101-106. [CrossRef] [PubMed]

52. Breitve, M.H.; Brønnick, K.; Chwiszczuk, L.J.; Hynninen, M.J.; Aarsland, D.; Rongve, A. Apathy is associated with faster global cognitive decline and early nursing home admission in dementia with Lewy bodies. Alzheimer's Res. Ther. 2018, 10. [CrossRef] [PubMed]

53. Hynninen, M.J.; Breitve, M.H.; Rongve, A.; Aarsland, D.; Nordhus, I.H. The frequency and correlates of anxiety in patients with first-time diagnosed mild dementia. Int. Psychogeriatr. 2012, 24, 1771-1778. [CrossRef]

54. Ffytche, D.H.; Creese, B.; Politis, M.; Chaudhuri, K.R.; Weintraub, D.; Ballard, C.; Aarsland, D. The psychosis spectrum in Parkinson disease. Nat. Rev. Neurol. 2017, 13, 81-95. [CrossRef]

55. Fénelon, G.; Mahieux, F.; Huon, R.; Ziégler, M. Hallucinations in Parkinson's disease. Prevalence, phenomenology and risk factors. Brain 2000, 123, 733-745. [CrossRef]

56. Gomperts, S.N. Lewy body dementias: Dementia with lewy bodies and Parkinson disease dementia. Continuum 2016, 22, 435-463. [CrossRef]

57. State, D.; Events, S.L. Clinical features of auditory hallucinations in patients with dementia with lewy bodies: A soundtrack of visual hallucinations. J. Clin. Psychiatry 2014, 2012, 11-12.

58. Pagonabarraga, J.; Martinez-Horta, S.; Fernández de Bobadilla, R.; Pérez, J.; Ribosa-Nogué, R.; Marín, J.; Pascual-Sedano, B.; García, C.; Gironell, A.; Kulisevsky, J. Minor hallucinations occur in drug-naive Parkinson's disease patients, even from the premotor phase. Mov. Disord. 2016, 31, 45-52. [CrossRef] 
59. Uchiyama, M.; Nishio, Y.; Yokoi, K.; Hirayama, K.; Imamura, T.; Shimomura, T.; Mori, E. Pareidolias: Complex visual illusions in dementia with Lewy bodies. Brain 2012, 135, 2458-2469. [CrossRef] [PubMed]

60. Uchiyama, M.; Nishio, Y.; Yokoi, K.; Hosokai, Y.; Takeda, A.; Mori, E. Pareidolia in Parkinson's disease without dementia: A positron emission tomography study. Park. Relat. Disord. 2015, 21, 603-609. [CrossRef] [PubMed]

61. Kövari, E.; Gold, G.; Herrmann, F.R.; Canuto, A.; Hof, P.R.; Bouras, C.; Giannakopoulos, P. Lewy body densities in the entorhinal and anterior cingulate cortex predict cognitive deficits in Parkinson's disease. Acta Neuropathol. 2003, 106, 83-88. [CrossRef]

62. Mattila, P.M.; Rinne, J.O.; Helenius, H.; Dickson, D.W.; Röyttä, M. Alpha-synuclein-immunoreactive cortical Lewy bodies are associated with cognitive impairment in Parkinson's disease. Acta Neuropathol. 2000, 100, 285-290. [CrossRef]

63. Braak, H.; Del Tredici, K.; Rüb, U.; De Vos, R.A.I.; Jansen Steur, E.N.H.; Braak, E. Staging of brain pathology related to sporadic Parkinson's disease. Neurobiol. Aging 2003, 24, 197-211. [CrossRef]

64. McKeith, I.G. Consensus guidelines for the clinical and pathologic diagnosis of dementia with Lewy bodies (DLB): Report of the Consortium on DLB International Workshop. In Proceedings of the Journal of Alzheimer's Disease; IOS Press: Amsterdam, The Netherlands, 2006; Volume 9, pp. 417-423.

65. Irwin, D.J.; White, M.T.; Toledo, J.B.; Xie, S.X.; Robinson, J.L.; Van Deerlin, V.; Lee, V.M.Y.; Leverenz, J.B.; Montine, T.J.; Duda, J.E.; et al. Neuropathologic substrates of Parkinson disease dementia. Ann. Neurol. 2012, 72, 587-598. [CrossRef]

66. Compta, Y.; Parkkinen, L.; O’Sullivan, S.S.; Vandrovcova, J.; Holton, J.L.; Collins, C.; Lashley, T.; Kallis, C.; Williams, D.R.; De Silva, R.; et al. Lewy- and Alzheimer-type pathologies in Parkinson's disease dementia: Which is more important? Brain 2011, 134, 1493-1505. [CrossRef]

67. Hepp, D.H.; Vergoossen, D.L.E.; Huisman, E.; Lemstra, A.W.; Bank, N.B.; Berendse, H.W.; Rozemuller, A.J.; Foncke, E.M.J.; Van De Berg, W.D.J. Distribution and load of amyloid-b pathology in Parkinson disease and dementia with lewy bodies. J. Neuropathol. Exp. Neurol. 2016, 75, 936-945. [CrossRef]

68. Clinton, L.K.; Blurton-Jones, M.; Myczek, K.; Trojanowski, J.Q.; LaFerla, F.M. Synergistic interactions between A $\beta$, tau, and $\alpha$-synuclein: Acceleration of neuropathology and cognitive decline. J. Neurosci. 2010, 30, 7281-7289. [CrossRef]

69. Walker, L.; McAleese, K.E.; Thomas, A.J.; Johnson, M.; Martin-Ruiz, C.; Parker, C.; Colloby, S.J.; Jellinger, K.; Attems, J. Neuropathologically mixed Alzheimer's and Lewy body disease: Burden of pathological protein aggregates differs between clinical phenotypes. Acta Neuropathol. 2015, 129, 729-748. [CrossRef]

70. Masliah, E.; Rockenstein, E.; Veinbergs, I.; Sagara, Y.; Mallory, M.; Hashimoto, M.; Mucke, L. $\beta$-Amyloid peptides enhance $\alpha$-synuclein accumulation and neuronal deficits in a transgenic mouse model linking Alzheimer's disease and Parkinson's disease. Proc. Natl. Acad. Sci. USA 2001, 98, 12245-12250. [CrossRef]

71. Giasson, B.I.; Forman, M.S.; Higuchi, M.; Golbe, L.I.; Graves, C.L.; Kotzbauer, P.T.; Trojanowski, J.Q.; Lee, V.M.Y. Initiation and synergistic fibrillization of tau and alpha-synuctein. Science 2003, 300, 636-640. [CrossRef]

72. Pletnikova, O.; West, N.; Lee, M.K.; Rudow, G.L.; Skolasky, R.L.; Dawson, T.M.; Marsh, L.; Troncoso, J.C. A $\beta$ deposition is associated with enhanced cortical $\alpha$-synuclein lesions in Lewy body diseases. Neurobiol. Aging 2005, 26, 1183-1192. [CrossRef] [PubMed]

73. Lashley, T.; Holton, J.L.; Gray, E.; Kirkham, K.; O'Sullivan, S.S.; Hilbig, A.; Wood, N.W.; Lees, A.J.; Revesz, T. Cortical $\alpha$-synuclein load is associated with amyloid- $\beta$ plaque burden in a subset of Parkinson's disease patients. Acta Neuropathol. 2008, 115, 417-425. [CrossRef] [PubMed]

74. Sierra, M.; Gelpi, E.; Martí, M.J.; Compta, Y. Lewy- and Alzheimer-type pathologies in midbrain and cerebellum across the Lewy body disorders spectrum. Neuropathol. Appl. Neurobiol. 2016, 42, 451-462. [CrossRef] [PubMed]

75. Kalaitzakis, M.E.; Graeber, M.B.; Gentleman, S.M.; Pearce, R.K.B. Striatal $\beta$-amyloid deposition in Parkinson disease with dementia. J. Neuropathol. Exp. Neurol. 2008, 67, 155-161. [CrossRef] [PubMed]

76. Hall, H.; Reyes, S.; Landeck, N.; Bye, C.; Leanza, G.; Double, K.; Thompson, L.; Halliday, G.; Kirik, D. Hippocampal Lewy pathology and cholinergic dysfunction are associated with dementia in Parkinson's disease. Brain 2014, 137, 2493-2508. [CrossRef] [PubMed]

77. Ruffmann, C.; Calboli, F.C.F.; Bravi, I.; Gveric, D.; Curry, L.K.; de Smith, A.; Pavlou, S.; Buxton, J.L.; Blakemore, A.I.F.; Takousis, P.; et al. Cortical Lewy bodies and $\mathrm{A} \beta$ burden are associated with prevalence and timing of dementia in Lewy body diseases. Neuropathol. Appl. Neurobiol. 2016, 42, 436-450. [CrossRef]

78. Schneider, J.A.; Arvanitakis, Z.; Yu, L.; Boyle, P.A.; Leurgans, S.E.; Bennett, D.A. Cognitive impairment, decline and fluctuations in older community-dwelling subjects with Lewy bodies. Brain 2012, 135, 3005-3014. [CrossRef]

79. Deramecourt, V.; Bombois, S.; Maurage, C.A.; Ghestem, A.; Drobecq, H.; Vanmechelen, E.; Lebert, F.; Pasquier, F.; Delacourte, A. Biochemical staging of synucleinopathy and amyloid deposition in dementia with Lewy bodies. J. Neuropathol. Exp. Neurol. 2006, 65, 278-288. [CrossRef]

80. Petrou, M.; Dwamena, B.A.; Foerster, B.R.; Maceachern, M.P.; Bohnen, N.I.; Müller, M.L.; Albin, R.L.; Frey, K.A. Amyloid deposition in Parkinson's disease and cognitive impairment: A systematic review. Mov. Disord. 2015, 30, 928-935. [CrossRef]

81. Fiorenzato, E.; Biundo, R.; Cecchin, D.; Frigo, A.C.; Kim, J.; Weis, L.; Strafella, A.P.; Antonini, A. Brain amyloid contribution to cognitive dysfunction in early-stage Parkinson's disease: The PPMI dataset. J. Alzheimer's Dis. 2018, 66, 229-237. [CrossRef]

82. Colom-Cadena, M.; Grau-Rivera, O.; Planellas, L.; Cerquera, C.; Morenas, E.; Helgueta, S.; Munoz, L.; Kulisevsky, J.; Marti, M.J.; Tolosa, E.; et al. Regional overlap of pathologies in lewy body disorders. J. Neuropathol. Exp. Neurol. 2017, 76, 216-224. [CrossRef] 
83. Kapasi, A.; DeCarli, C.; Schneider, J.A. Impact of multiple pathologies on the threshold for clinically overt dementia. Acta Neuropathol. 2017, 134, 171-186. [CrossRef]

84. Smith, C.; Malek, N.; Grosset, K.; Cullen, B.; Gentleman, S.; Grosset, D.G. Neuropathology of dementia in patients with Parkinson's disease: A systematic review of autopsy studies. J. Neurol. Neurosurg. Psychiatry 2019, 90, 1234-1243. [CrossRef]

85. Halliday, G.M.; Song, Y.J.C.; Harding, A.J. Striatal $\beta$-amyloid in dementia with Lewy bodies but not Parkinson's disease. J. Neural Transm. 2011, 118, 713-719. [CrossRef]

86. Jellinger, K.A.; Attems, J. Does striatal pathology distinguish Parkinson disease with dementia and dementia with Lewy bodies? Acta Neuropathol. 2006, 112, 253-260. [CrossRef]

87. Shah, N.; Frey, K.A.; Müller, M.L.T.M.; Petrou, M.; Kotagal, V.; Koeppe, R.A.; Scott, P.J.H.; Albin, R.L.; Bohnen, N.I. Striatal and cortical $\beta$-amyloidopathy and cognition in Parkinson's disease. Mov. Disord. 2016, 31, 111-117. [CrossRef]

88. Kalaitzakis, M.E.; Pearce, R.K.B.; Gentleman, S.M. Clinical correlates of pathology in the claustrum in Parkinson's disease and dementia with Lewy bodies. Neurosci. Lett. 2009, 461, 12-15. [CrossRef]

89. Walker, L.; Stefanis, L.; Attems, J. Clinical and neuropathological differences between Parkinson's disease, Parkinson's disease dementia and dementia with Lewy bodies-Current issues and future directions. J. Neurochem. 2019, 150, 467-474. [CrossRef]

90. Horvath, J.; Herrmann, F.R.; Burkhard, P.R.; Bouras, C.; Kövari, E. Neuropathology of dementia in a large cohort of patients with Parkinson's disease. Park. Relat. Disord. 2013, 19, 864-868. [CrossRef]

91. Coughlin, D.G.; Hurtig, H.I.; Irwin, D.J. Pathological influences on clinical heterogeneity in Lewy body diseases. Mov. Disord. 2020, 35, 5-19. [CrossRef]

92. Buchman, A.S.; Yu, L.; Wilson, R.S.; Leurgans, S.E.; Nag, S.; Shulman, J.M.; Barnes, L.L.; Schneider, J.A.; Bennett, D.A. Progressive parkinsonism in older adults is related to the burden of mixed brain pathologies. Neurology 2019, 92, E1821-E1830. [CrossRef] [PubMed]

93. Beyer, M.K.; Larsen, J.P.; Aarsland, D. Gray matter atrophy in Parkinson disease with dementia and dementia with Lewy bodies. Neurology 2007, 69, 747-754. [CrossRef] [PubMed]

94. Burton, E.J.; McKeith, I.G.; Burn, D.J.; Williams, E.D.; O’Brien, J.T. Cerebral atrophy in Parkinson's disease with and without dementia: A comparison with Alzheimer's disease, dementia with Lewy bodies and controls. Brain 2004, 127. [CrossRef] [PubMed]

95. Borroni, B.; Premi, E.; Formenti, A.; Turrone, R.; Alberici, A.; Cottini, E.; Rizzetti, C.; Gasparotti, R.; Padovani, A. Structural and functional imaging study in dementia with Lewy bodies and Parkinson's disease dementia. Park. Relat. Disord. 2015, 21, 1049-1055. [CrossRef] [PubMed]

96. Goldman, J.G.; Stebbins, G.T.; Bernard, B.; Stoub, T.R.; Goetz, C.G.; deToledo-Morrell, L. Entorhinal cortex atrophy differentiates Parkinson's disease patients with and without dementia. Mov. Disord. 2012, 27, 727-734. [CrossRef] [PubMed]

97. Weil, R.S.; Hsu, J.K.; Darby, R.R.; Soussand, L.; Fox, M.D. Neuroimaging in Parkinson's disease dementia: Connecting the dots. Brain Commun. 2019, 1, fcz006. [CrossRef]

98. Compta, Y.; Pereira, J.B.; Ríos, J.; Ibarretxe-Bilbao, N.; Junqué, C.; Bargalló, N.; Cámara, A.; Buongiorno, M.; Fernández, M.; Pont-Sunyer, C.; et al. Combined dementia-risk biomarkers in Parkinson's disease: A prospective longitudinal study. Park. Relat. Disord. 2013, 19, 717-724. [CrossRef]

99. Lee, J.E.; Cho, K.H.; Song, S.K.; Kim, H.J.; Lee, H.S.; Sohn, Y.H.; Lee, P.H. Exploratory analysis of neuropsychological and neuroanatomical correlates of progressive mild cognitive impairment in Parkinson's disease. J. Neurol. Neurosurg. Psychiatry 2014, 85, 7-16. [CrossRef]

100. Zheng, D.; Chen, C.; Song, W.C.; Yi, Z.Q.; Zhao, P.W.; Zhong, J.G.; Dai, Z.Y.; Shi, H.C.; Pan, P.L. Regional gray matter reductions associated with mild cognitive impairment in Parkinson's disease: A meta-analysis of voxel-based morphometry studies. Behav. Brain Res. 2019, 371, 111973. [CrossRef]

101. Kandiah, N.; Zainal, N.H.; Narasimhalu, K.; Chander, R.J.; Ng, A.; Mak, E.; Au, W.L.; Sitoh, Y.Y.; Nadkarni, N.; Tan, L.C.S. Hippocampal volume and white matter disease in the prediction of dementia in Parkinson's disease. Park. Relat. Disord. 2014, 20, 1203-1208. [CrossRef]

102. Lee, J.E.; Park, B.; Song, S.K.; Sohn, Y.H.; Park, H.J.; Lee, P.H. A comparison of gray and white matter density in patients with Parkinson's disease dementia and dementia with Lewy bodies using voxel-based morphometry. Mov. Disord. 2010, 25, 28-34. [CrossRef]

103. Yousaf, T.; Dervenoulas, G.; Valkimadi, P.E.; Politis, M. Neuroimaging in Lewy body dementia. J. Neurol. 2019, 266, 1. [CrossRef]

104. Burton, E.J.; McKeith, I.G.; Burn, D.J.; Firbank, M.J.; O’Brien, J.T. Progression of white matter hyperintensities in Alzheimer disease, dementia with Lewy bodies, and Parkinson disease dementia: A comparison with normal aging. Am. J. Geriatr. Psychiatry 2006, 14, 842-849. [CrossRef]

105. Hayashi, H.; Kawakatsu, S.; Suzuki, A.; Shibuya, Y.; Kobayashi, R.; Sato, C.; Otani, K. Application of the VSRAD, a specific and sensitive voxel-based morphometry, to comparison of Entorhinal cortex atrophy between dementia with Lewy bodies and Alzheimer's disease. Dement. Geriatr. Cogn. Disord. 2013, 34, 328-331. [CrossRef]

106. Watson, R.; Colloby, S.J. Imaging in dementia with Lewy bodies: An overview. J. Geriatr. Psychiatry Neurol. 2016, $29,254-260$. [CrossRef] 
107. Blanc, F.; Colloby, S.J.; Cretin, B.; De Sousa, P.L.; Demuynck, C.; O’Brien, J.T.; Martin-Hunyadi, C.; McKeith, I.; Philippi, N.; Taylor, J.P. Grey matter atrophy in prodromal stage of dementia with Lewy bodies and Alzheimer's disease. Alzheimer's Res. Ther. 2016, 8, 31. [CrossRef]

108. Kantarci, K.; Lesnick, T.; Ferman, T.J.; Przybelski, S.A.; Boeve, B.F.; Smith, G.E.; Kremers, W.K.; Knopman, D.S.; Jack, C.R.; Petersen, R.C. Hippocampal volumes predict risk of dementia with Lewy bodies in mild cognitive impairment. Neurology 2016, 87, 2317-2323. [CrossRef]

109. Delgado-Alvarado, M.; Gago, B.; Navalpotro-Gomez, I.; Jiménez-Urbieta, H.; Rodriguez-Oroz, M.C. Biomarkers for dementia and mild cognitive impairment in Parkinson's disease. Mov. Disord. 2016, 31, 861-881. [CrossRef]

110. Melzer, T.R.; Watts, R.; Macaskill, M.R.; Pitcher, T.L.; Livingston, L.; Keenan, R.J.; Dalrymple-Alford, J.C.; Anderson, T.J. White matter microstructure deteriorates across cognitive stages in Parkinson disease. Neurology 2013, 80, 1841-1849. [CrossRef]

111. Kamagata, K.; Motoi, Y.; Tomiyama, H.; Abe, O.; Ito, K.; Shimoji, K.; Suzuki, M.; Hori, M.; Nakanishi, A.; Sano, T.; et al. Relationship between cognitive impairment and white-matter alteration in Parkinson's disease with dementia: Tract-based spatial statistics and tract-specific analysis. Eur. Radiol. 2013, 23, 1946-1955. [CrossRef]

112. Chen, B.; Fan, G.G.; Liu, H.; Wang, S. Changes in anatomical and functional connectivity of Parkinson's disease patients according to cognitive status. Eur. J. Radiol. 2015, 84, 1318-1324. [CrossRef]

113. Hattori, T.; Orimo, S.; Aoki, S.; Ito, K.; Abe, O.; Amano, A.; Sato, R.; Sakai, K.; Mizusawa, H. Cognitive status correlates with white matter alteration in Parkinson's disease. Hum. Brain Mapp. 2012, 33, 727-739. [CrossRef]

114. Agosta, F.; Canu, E.; Stefanova, E.; Sarro, L.; Tomić, A.; Špica, V.; Comi, G.; Kostić, V.S.; Filippi, M. Mild cognitive impairment in Parkinson's disease is associated with a distributed pattern of brain white matter damage. Hum. Brain Mapp. 2014, 35, 1921-1929. [CrossRef] [PubMed]

115. Bledsoe, I.O.; Stebbins, G.T.; Merkitch, D.; Goldman, J.G. White matter abnormalities in the corpus callosum with cognitive impairment in Parkinson disease. Neurology 2018, 91, E2244-E2255. [CrossRef] [PubMed]

116. Watson, R.; Blamire, A.M.; Colloby, S.J.; Wood, J.S.; Barber, R.; He, J.; O’Brien, J.T. Characterizing dementia with Lewy bodies by means of diffusion tensor imaging. Neurology 2012, 79, 906-914. [CrossRef] [PubMed]

117. Yao, N.; Cheung, C.; Pang, S.; Shek-kwan Chang, R.; Lau, K.K.; Suckling, J.; Yu, K.; Ka-Fung Mak, H.; Chua, S.E.; Ho, S.L.; et al. Multimodal MRI of the hippocampus in Parkinson's disease with visual hallucinations. Brain Struct. Funct. 2016, 221, 287-300. [CrossRef] [PubMed]

118. Delli Pizzi, S.; Maruotti, V.; Taylor, J.P.; Franciotti, R.; Caulo, M.; Tartaro, A.; Thomas, A.; Onofrj, M.; Bonanni, L. Relevance of subcortical visual pathways disruption to visual symptoms in dementia with Lewy bodies. Cortex 2014, 59, 12-21. [CrossRef]

119. Kantarci, K.; Avula, R.; Senjem, M.L.; Samikoglu, A.R.; Zhang, B.; Weigand, S.D.; Przybelski, S.A.; Edmonson, H.A.; Vemuri, P.; Knopman, D.S.; et al. Dementia with Lewy bodies and Alzheimer disease: Neurodegenerative patterns characterized by DTI. Neurology 2010, 74, 1814-1821. [CrossRef]

120. Balážová, Z.; Nováková, M.; Minsterová, A.; Rektorová, I. Structural and functional magnetic resonance imaging of dementia with Lewy bodies. Int. Rev. Neurobiol. 2019, 144, 95-141. [CrossRef]

121. Lee, J.E.; Park, H.J.; Park, B.S.; Song, S.K.; Sohn, Y.H.; Lee, J.D.; Lee, P.H. A comparative analysis of cognitive profiles and white-matter alterations using voxel-based diffusion tensor imaging between patients with Parkinson's disease dementia and dementia with Lewy bodies. J. Neurol. Neurosurg. Psychiatry 2010, 81, 320-326. [CrossRef]

122. Pietracupa, S.; Martin-Bastida, A.; Piccini, P. Iron metabolism and its detection through MRI in parkinsonian disorders: A systematic review. Neurol. Sci. 2017, 38, 2095-2101. [CrossRef]

123. Barber, T.R.; Griffanti, L.; Bradley, K.M.; McGowan, D.R.; Lo, C.; Mackay, C.E.; Hu, M.T.; Klein, J.C. Nigrosome 1 imaging in REM sleep behavior disorder and its association with dopaminergic decline. Ann. Clin. Transl. Neurol. 2020, 7, 26-35. [CrossRef]

124. Schwarz, S.T.; Afzal, M.; Morgan, P.S.; Bajaj, N.; Gowland, P.A.; Auer, D.P. The "swallow tail" appearance of the healthy nigrosome-A new accurate test of Parkinson's disease: A case-control and retrospective cross-sectional MRI study at 3T. PLoS ONE 2014, 9, e93814. [CrossRef]

125. Rizzo, G.; De Blasi, R.; Capozzo, R.; Tortelli, R.; Barulli, M.R.; Liguori, R.; Grasso, D.; Logroscino, G. Loss of swallow tail sign on susceptibility-weighted imaging in dementia with Lewy bodies. J. Alzheimer's Dis. 2019, 67, 61-65. [CrossRef]

126. Oustwani, C.S.; Korutz, A.W.; Lester, M.S.; Kianirad, Y.; Simuni, T.; Hijaz, T.A. Can loss of the swallow tail sign help distinguish between Parkinson Disease and the Parkinson-Plus syndromes? Clin. Imaging 2017, 44, 66-69. [CrossRef]

127. Murakami, Y.; Kakeda, S.; Watanabe, K.; Ueda, I.; Ogasawara, A.; Moriya, J.; Ide, S.; Futatsuya, K.; Sato, T.; Okada, K.; et al Usefulness of quantitative susceptibility mapping for the diagnosis of Parkinson disease. Am. J. Neuroradiol. 2015, 36, 1102-1108. [CrossRef]

128. Langkammer, C.; Pirpamer, L.; Seiler, S.; Deistung, A.; Schweser, F.; Franthal, S.; Homayoon, N.; Katschnig-Winter, P.; KoeglWallner, M.; Pendl, T.; et al. Quantitative susceptibility mapping in Parkinson's disease. PLoS ONE 2016, 11, e162460. [CrossRef]

129. Martin-Bastida, A.; Lao-Kaim, N.P.; Loane, C.; Politis, M.; Roussakis, A.A.; Valle-Guzman, N.; Kefalopoulou, Z.; Paul-Visse, G.; Widner, H.; Xing, Y.; et al. Motor associations of iron accumulation in deep grey matter nuclei in Parkinson's disease: A cross-sectional study of iron-related magnetic resonance imaging susceptibility. Eur. J. Neurol. 2017, 24, 357-365. [CrossRef]

130. He, N.; Ling, H.; Ding, B.; Huang, J.; Zhang, Y.; Zhang, Z.; Liu, C.; Chen, K.; Yan, F. Region-specific disturbed iron distribution in early idiopathic Parkinson's disease measured by quantitative susceptibility mapping. Hum. Brain Mapp. 2015, 36, 4407-4420. [CrossRef] 
131. Guan, X.; Xuan, M.; Gu, Q.; Huang, P.; Liu, C.; Wang, N.; Xu, X.; Luo, W.; Zhang, M. Regionally progressive accumulation of iron in Parkinson's disease as measured by quantitative susceptibility mapping. NMR Biomed. 2017, 30, 1-17. [CrossRef]

132. Chen, Q.; Chen, Y.; Zhang, Y.; Wang, F.; Yu, H.; Zhang, C.; Jiang, Z.; Luo, W. Iron deposition in Parkinson's disease by quantitative susceptibility mapping. BMC Neurosci. 2019, 20, 23. [CrossRef]

133. Thomas, G.E.C.; Leyland, L.A.; Schrag, A.E.; Lees, A.J.; Acosta-Cabronero, J.; Weil, R.S. Brain iron deposition is linked with cognitive severity in Parkinson's disease. J. Neurol. Neurosurg. Psychiatry 2020, 91, 418-425. [CrossRef]

134. Cogswell, P.M.; Wiste, H.J.; Senjem, M.L.; Gunter, J.L.; Weigand, S.D.; Schwarz, C.G.; Arani, A.; Therneau, T.M.; Lowe, V.J.; Knopman, D.S.; et al. Associations of quantitative susceptibility mapping with Alzheimer's disease clinical and imaging markers. Neuroimage 2021, 224, 117433. [CrossRef]

135. Ravanfar, P.; Loi, S.M.; Syeda, W.T.; Van Rheenen, T.E.; Bush, A.I.; Desmond, P.; Cropley, V.L.; Lane, D.J.R.; Opazo, C.M.; Moffat, B.A.; et al. Systematic Review: Quantitative Susceptibility Mapping (QSM) of Brain Iron Profile in Neurodegenerative Diseases. Front. Neurosci. 2021, 15, 618435. [CrossRef] [PubMed]

136. Baggio, H.C.; Segura, B.; Sala-Llonch, R.; Marti, M.J.; Valldeoriola, F.; Compta, Y.; Tolosa, E.; Junqué, C. Cognitive impairment and resting-state network connectivity in Parkinson's disease. Hum. Brain Mapp. 2015, 36, 199-212. [CrossRef]

137. Bezdicek, O.; Ballarini, T.; Růžička, F.; Roth, J.; Mueller, K.; Jech, R.; Schroeter, M.L. Mild cognitive impairment disrupts attention network connectivity in Parkinson's disease: A combined multimodal MRI and meta-analytical study. Neuropsychologia 2018, 112, 105-115. [CrossRef]

138. Schumacher, J.; Peraza, L.R.; Firbank, M.; Thomas, A.J.; Kaiser, M.; Gallagher, P.; O’Brien, J.T.; Blamire, A.M.; Taylor, J.P. Functional connectivity in dementia with Lewy bodies: A within- and between-network analysis. Hum. Brain Mapp. 2018, 39, 1118-1129. [CrossRef]

139. Peraza, L.R.; Kaiser, M.; Firbank, M.; Graziadio, S.; Bonanni, L.; Onofrj, M.; Colloby, S.J.; Blamire, A.; O’Brien, J.; Taylor, J.P. FMRI resting state networks and their association with cognitive fluctuations in dementia with Lewy bodies. NeuroImage Clin. 2014, 4, 558-565. [CrossRef] [PubMed]

140. Rieckmann, A.; Gomperts, S.N.; Johnson, K.A.; Growdon, J.H.; Van Dijk, K.R.A. Putamen-midbrain functional connectivity is related to striatal dopamine transporter availability in patients with Lewy body diseases. NeuroImage Clin. 2015, 8, 554-559. [CrossRef] [PubMed]

141. Peraza, L.R.; Colloby, S.J.; Deboys, L.; O’Brien, J.T.; Kaiser, M.; Taylor, J.P. Regional functional synchronizations in dementia with Lewy bodies and Alzheimer's disease. Int. Psychogeriatr. 2016, 28, 1143-1151. [CrossRef] [PubMed]

142. Franciotti, R.; Falasca, N.W.; Bonanni, L.; Anzellotti, F.; Maruotti, V.; Comani, S.; Thomas, A.; Tartaro, A.; Taylor, J.P.; Onofrj, M. Default network is not hypoactive in dementia with fluctuating cognition: An Alzheimer disease/dementia with Lewy bodies comparison. Neurobiol. Aging 2013, 34, 1148-1158. [CrossRef]

143. Peraza, L.R.; Colloby, S.J.; Firbank, M.J.; Greasy, G.S.; McKeith, I.G.; Kaiser, M.; O’Brien, J.; Taylor, J.P. Resting state in Parkinson's disease dementia and dementia with Lewy bodies: Commonalities and differences. Int. J. Geriatr. Psychiatry 2015, 30, 1135-1146. [CrossRef] [PubMed]

144. Hu, X.S.; Okamura, N.; Arai, H.; Higuchi, M.; Matsui, T.; Tashiro, M.; Shinkawa, M.; Itoh, M.; Ido, T.; Sasaki, H. 18F-fluorodopa PET study of striatal dopamine uptake in the diagnosis of dementia with Lewy bodies. Neurology 2000, 55, 1575-1576. [CrossRef] [PubMed]

145. McKeith, I.; O’Brien, J.; Walker, Z.; Tatsch, K.; Booij, J.; Darcourt, J.; Padovani, A.; Giubbini, R.; Bonuccelli, U.; Volterrani, D.; et al. Sensitivity and specificity of dopamine transporter imaging with 123I-FP-CIT SPECT in dementia with Lewy bodies: A phase III, multicentre study. Lancet Neurol. 2007, 6, 305-313. [CrossRef]

146. Thomas, A.J.; Attems, J.; Colloby, S.J.; O’Brien, J.T.; Mckeith, I.; Walker, R.; Lee, L.; Burn, D.; Lett, D.J.; Walker, Z. Autopsy validation of 123 I-FP-CIT dopaminergic neuroimaging for the diagnosis of DLB. Neurology 2017, 88, 276-283. [CrossRef]

147. Rossi, C.; Volterrani, D.; Nicoletti, V.; Manca, G.; Frosini, D.; Kiferle, L.; Unti, E.; De Feo, P.; Bonuccelli, U.; Ceravolo, R. "Parkinson-dementia" diseases: A comparison by double tracer SPECT studies. Park. Relat. Disord. 2009, 15, 762-766. [CrossRef]

148. Yonga, S.W.; Yoonb, J.K.; Leea, Y.S.A.; Lee, P.H. A comparison of cerebral glucose metabolism in Parkinson's disease, Parkinson's disease dementia and dementia with Lewy bodies. Eur. J. Neurol. 2007, 14, 1357-1362. [CrossRef] [PubMed]

149. O’Brien, J.T.; Firbank, M.J.; Davison, C.; Barnett, N.; Bamford, C.; Donaldson, C.; Olsen, K.; Herholz, K.; Williams, D.; Lloyd, J. 18F-FDG PET and perfusion SPECT in the diagnosis of Alzheimer and Lewy body dementias. J. Nucl. Med. 2014, 55, 1959-1965. [CrossRef]

150. González-Redondo, R.; García-García, D.; Clavero, P.; Gasca-Salas, C.; García-Eulate, R.; Zubieta, J.L.; Arbizu, J.; Obeso, J.A.; Rodríguez-Oroz, M.C. Grey matter hypometabolism and atrophy in Parkinson's disease with cognitive impairment: A two-step process. Brain 2014, 137, 2356-2367. [CrossRef]

151. Higuchi, M.; Tashiro, M.; Arai, H.; Okamura, N.; Hara, S.; Higuchi, S.; Itoh, M.; Shin, R.W.; Trojanowski, J.Q.; Sasaki, H. Glucose hypometabolism and neuropathological correlates in brains of dementia with Lewy bodies. Exp. Neurol. 2000, 162, 247-256. [CrossRef] [PubMed]

152. Mosconi, L.; Tsui, W.H.; Herholz, K.; Pupi, A.; Drzezga, A.; Lucignani, G.; Reiman, E.M.; Holthoff, V.; Kalbe, E.; Sorbi, S.; et al. Multicenter standardized 18F-FDG PET diagnosis of mild cognitive impairment, Alzheimer's disease, and other dementias. J. Nucl. Med. 2008, 49, 390-398. [CrossRef] [PubMed] 
153. Odagiri, H.; Baba, T.; Nishio, Y.; Iizuka, O.; Matsuda, M.; Inoue, K.; Kikuchi, A.; Hasegawa, T.; Aoki, M.; Takeda, A.; et al. On the utility of MIBG SPECT/CT in evaluating cardiac sympathetic dysfunction in lewy body diseases. PLoS ONE 2016, 11, e152746. [CrossRef] [PubMed]

154. Suzuki, M.; Kurita, A.; Hashimoto, M.; Fukumitsu, N.; Abo, M.; Ito, Y.; Urashima, M.; Inoue, K. Impaired myocardial 123Imetaiodobenzylguanidine uptake in Lewy body disease: Comparison between dementia with Lewy bodies and Parkinson's disease. J. Neurol. Sci. 2006, 240, 15-19. [CrossRef] [PubMed]

155. Lamotte, G.; Morello, R.; Lebasnier, A.; Agostini, D.; Defer, G.L. Accuracy and cutoff values of delayed heart to mediastinum ratio with 123I-metaiodobenzylguanidine cardiac scintigraphy for Lewy body disease diagnoses. BMC Neurol. 2015, 15, 83. [CrossRef]

156. Watanabe, H.; Ieda, T.; Katayama, T.; Takeda, A.; Aiba, I.; Doyu, M.; Hirayama, M.; Sobue, G. Cardiac 123I-metaiodobenzylguanidine (MIBG) uptake in dementia with lewy bodies: Comparison with Alzheimer's disease. J. Neurol. Neurosurg. Psychiatry 2001, 70, 781-783. [CrossRef]

157. Orimo, S.; Yogo, M.; Nakamura, T.; Suzuki, M.; Watanabe, H. 123I-meta-iodobenzylguanidine (MIBG) cardiac scintigraphy in $\alpha$-synucleinopathies. Ageing Res. Rev. 2016, 30, 122-133. [CrossRef]

158. Chung, E.J.; Kim, S.J. (123)I-Metaiodobenzylguanidine Myocardial Scintigraphy in Lewy Body-Related Disorders: A Literature Review. J. Mov. Disord. 2015, 8, 55-66. [CrossRef]

159. Armstrong, M.J. Lewy body dementias. Contin. Lifelong Learn. Neurol. 2019, 25, 128-146. [CrossRef]

160. Donaghy, P.; Thomas, A.J.; O’Brien, J.T. Amyloid PET imaging in lewy body disorders. Am. J. Geriatr. Psychiatry 2015, $23,23-37$. [CrossRef]

161. Gomperts, S.N. Imaging the role of amyloid in PD dementia and dementia with Lewy bodies. Curr. Neurol. Neurosci. Rep. 2014, 14, 472. [CrossRef]

162. Gomperts, S.N.; Marquie, M.; Locascio, J.J.; Bayer, S.; Johnson, K.A.; Growdon, J.H. PET radioligands reveal the basis of dementia in Parkinson's disease and dementia with lewy bodies. Neurodegener. Dis. 2016, 16, 118-124. [CrossRef]

163. Gomperts, S.N.; Locascio, J.J.; Marquie, M.; Santarlasci, A.L.; Rentz, D.M.; Maye, J.; Johnson, K.A.; Growdon, J.H. Brain amyloid and cognition in Lewy body diseases. Mov. Disord. 2012, 27, 965-973. [CrossRef]

164. Foster, E.R.; Campbell, M.C.; Burack, M.A.; Hartlein, J.; Flores, H.P.; Cairns, N.J.; Hershey, T.; Perlmutter, J.S. Amyloid imaging of Lewy body-associated disorders. Mov. Disord. 2010, 25, 2516-2523. [CrossRef]

165. Shirvan, J.; Clement, N.; Ye, R.; Katz, S.; Schultz, A.; Johnson, K.A.; Gomez-Isla, T.; Frosch, M.; Growdon, J.H.; Gomperts, S.N. Neuropathologic correlates of amyloid and dopamine transporter imaging in Lewy body disease. Neurology 2019, 93, E476-E484. [CrossRef]

166. Chen, Q.; Lowe, V.J.; Boeve, B.F.; Przybelski, S.A.; Miyagawa, T.; Senjem, M.L.; Jack, C.R.; Lesnick, T.G.; Kremers, W.K.; Fields, J.A.; et al. $\beta$-amyloid PET and 123 I-FP-CIT SPECT in mild cognitive impairment at risk for Lewy body dementia. Neurology 2021, 96, e1180-e1189. [CrossRef]

167. Nedelska, Z.; Schwarz, C.G.; Lesnick, T.G.; Boeve, B.F.; Przybelski, S.A.; Lowe, V.J.; Kremers, W.K.; Gunter, J.L.; Senjem, M.L.; Graff-Radford, J.; et al. Association of longitudinal $\beta$-amyloid accumulation determined by positron emission tomography with clinical and cognitive decline in adults with probable Lewy body dementia. JAMA Netw. Open 2019, 2, e1916439. [CrossRef]

168. Irwin, D.J.; Grossman, M.; Weintraub, D.; Hurtig, H.I.; Duda, J.E.; Xie, S.X.; Lee, E.B.; Van Deerlin, V.M.; Lopez, O.L.; Kofler, J.K.; et al. Neuropathological and genetic correlates of survival and dementia onset in synucleinopathies: A retrospective analysis. Lancet Neurol. 2017, 16, 55. [CrossRef]

169. Gomperts, S.N.; Locascio, J.J.; Makaretz, S.J.; Schultz, A.; Caso, C.; Vasdev, N.; Sperling, R.; Growdon, J.H.; Dickerson, B.C.; Johnson, K. Tau positron emission tomographic imaging in the lewy body diseases. JAMA Neurol. 2016, 73, 1334-1341. [CrossRef]

170. Hall, B.; Mak, E.; Cervenka, S.; Aigbirhio, F.I.; Rowe, J.B.; O’Brien, J.T. In vivo tau PET imaging in dementia: Pathophysiology, radiotracer quantification, and a systematic review of clinical findings. Ageing Res. Rev. 2017, 36, 50-63. [CrossRef]

171. Whitwell, J.L. Tau imaging in Parkinsonism: What have we learned so far? Mov. Disord. Clin. Pract. 2018, 5, 118-130. [CrossRef]

172. Kantarci, K.; Lowe, V.J.; Boeve, B.F.; Senjem, M.L.; Tosakulwong, N.; Lesnick, T.G.; Spychalla, A.J.; Gunter, J.L.; Fields, J.A.; Graff-Radford, J.; et al. AV-1451 tau and $\beta$-amyloid positron emission tomography imaging in dementia with Lewy bodies. Ann. Neurol. 2017, 81, 58-67. [CrossRef]

173. Kotzbauer, P.T.; Tu, Z.; Mach, R.H. Current status of the development of PET radiotracers for imaging alpha synuclein aggregates in Lewy bodies and Lewy neurites. Clin. Transl. Imaging 2017, 5, 3-14. [CrossRef]

174. Verdurand, M.; Levigoureux, E.; Zeinyeh, W.; Berthier, L.; Mendjel-Herda, M.; Cadarossanesaib, F.; Bouillot, C.; Iecker, T.; Terreux, R.; Lancelot, S.; et al. In silico, in vitro, and in vivo evaluation of new candidates for $\alpha$-synuclein PET imaging. Mol. Pharm. 2018, 15, 3153-3166. [CrossRef]

175. Zhang, X.; Jin, H.; Padakanti, P.; Li, J.; Yang, H.; Fan, J.; Mach, R.; Kotzbauer, P.; Tu, Z. Radiosynthesis and in vivo evaluation of two PET radioligands for imaging $\alpha$-synuclein. Appl. Sci. 2014, 4, 66-78. [CrossRef]

176. Maurer, A.; Leonov, A.; Ryazanov, S.; Herfert, K.; Kuebler, L.; Buss, S.; Schmidt, F.; Weckbecker, D.; Linder, R.; Bender, D.; et al. 11C Radiolabeling of anle253b: A putative PET tracer for Parkinson's disease that binds to $\alpha$-synuclein fibrils in vitro and crosses the blood-brain barrier. ChemMedChem 2020, 15, 411-415. [CrossRef]

177. Surendranathan, A.; Su, L.; Mak, E.; Passamonti, L.; Hong, Y.T.; Arnold, R.; Rodríguez, P.V.; Bevan-Jones, W.R.; Brain, S.A.E.; Fryer, T.D.; et al. Early microglial activation and peripheral inflammation in dementia with Lewy bodies. Brain 2018, 141, 3415-3427. [CrossRef] 
178. Nicastro, N.; Surendranathan, A.; Mak, E.; Rowe, J.B.; O’Brien, J.T. 11C-PK11195 PET imaging and white matter changes in Parkinson's disease dementia. Ann. Clin. Transl. Neurol. 2019, 6, 2133-2136. [CrossRef]

179. Iannaccone, S.; Cerami, C.; Alessio, M.; Garibotto, V.; Panzacchi, A.; Olivieri, S.; Gelsomino, G.; Moresco, R.M.; Perani, D. In vivo microglia activation in very early dementia with Lewy bodies, comparison with Parkinson's disease. Park. Relat. Disord. 2013, 19, 47-52. [CrossRef]

180. Gerhard, A.; Pavese, N.; Hotton, G.; Turkheimer, F.; Es, M.; Hammers, A.; Eggert, K.; Oertel, W.; Banati, R.B.; Brooks, D.J. In vivo imaging of microglial activation with [11C](R)-PK11195 PET in idiopathic Parkinson's disease. Neurobiol. Dis. 2006, 21, 404-412. [CrossRef] [PubMed]

181. Bartels, A.L.; Willemsen, A.T.M.; Doorduin, J.; de Vries, E.F.J.; Dierckx, R.A.; Leenders, K.L. [11C]-PK11195 PET: Quantification of neuroinflammation and a monitor of anti-inflammatory treatment in Parkinson's disease? Park. Relat. Disord. 2010, 16, 57-59. [CrossRef] [PubMed]

182. Fan, Z.; Aman, Y.; Ahmed, I.; Chetelat, G.; Landeau, B.; Ray Chaudhuri, K.; Brooks, D.J.; Edison, P. Influence of microglial activation on neuronal function in Alzheimer's and Parkinson's disease dementia. Alzheimer's Dement. 2015, 11, 608-621.e7. [CrossRef]

183. Edison, P.; Ahmed, I.; Fan, Z.; Hinz, R.; Gelosa, G.; Ray Chaudhuri, K.; Walker, Z.; Turkheimer, F.E.; Brooks, D.J. Microglia, amyloid, and glucose metabolism in parkinson's disease with and without dementia. Neuropsychopharmacology 2013, 38, 938-949. [CrossRef] [PubMed]

184. Rodríguez-Chinchilla, T.; Quiroga-Varela, A.; Molinet-Dronda, F.; Belloso-Iguerategui, A.; Merino-Galan, L.; Jimenez-Urbieta, H.; Gago, B.; Rodriguez-Oroz, M.C. [18F]-DPA-714 PET as a specific in vivo marker of early microglial activation in a rat model of progressive dopaminergic degeneration. Eur. J. Nucl. Med. Mol. Imaging 2020, 47, 2602-2612. [CrossRef] [PubMed]

185. Molinuevo, J.L.; Ayton, S.; Batrla, R.; Bednar, M.M.; Bittner, T.; Cummings, J.; Fagan, A.M.; Hampel, H.; Mielke, M.M.; Mikulskis, A.; et al. Current state of Alzheimer's fluid biomarkers. Acta Neuropathol. 2018, 136, 821. [CrossRef] [PubMed]

186. Parnetti, L.; Paciotti, S.; Farotti, L.; Bellomo, G.; Sepe, F.N.; Eusebi, P. Parkinson's and Lewy body dementia CSF biomarkers. Clin. Chim. Acta 2019, 495, 318-325. [CrossRef]

187. Siderowf, A.; Xie, S.X.; Hurtig, H.; Weintraub, D.; Duda, J.; Chen-Plotkin, A.; Shaw, L.M.; Van Deerlin, V.; Trojanowski, J.Q.; Clark, C. CSF amyloid $\beta$ 1-42 predicts cognitive decline in Parkinson disease. Neurology 2010, 75, 1055-1061. [CrossRef]

188. Liu, C.; Cholerton, B.; Shi, M.; Ginghina, C.; Cain, K.C.; Auinger, P.; Zhang, J. CSF tau and tau/A $\beta 42$ predict cognitive decline in Parkinson's disease. Park. Relat. Disord. 2015, 21, 271-276. [CrossRef]

189. Ferreira, D.; Przybelski, S.A.; Lesnick, T.G.; Lemstra, A.W.; Londos, E.; Blanc, F.; Nedelska, Z.; Schwarz, C.G.; Graff-Radford, J.; Senjem, M.L.; et al. $\beta$-Amyloid and tau biomarkers and clinical phenotype in dementia with Lewy bodies. Neurology 2020, 95, e3257-e3268. [CrossRef]

190. Van Steenoven, I.; Aarsland, D.; Weintraub, D.; Londos, E.; Blanc, F.; Van Der Flier, W.M.; Teunissen, C.E.; Mollenhauer, B.; Fladby, T.; Kramberger, M.G.; et al. Cerebrospinal fluid Alzheimer's disease biomarkers across the spectrum of lewy body diseases: Results from a large multicenter cohort. J. Alzheimer's Dis. 2016, 54, 287-295. [CrossRef]

191. Van Steenoven, I.; Van Der Flier, W.M.; Scheltens, P.; Teunissen, C.E.; Lemstra, A.W. Amyloid- $\beta$ peptides in cerebrospinal fluid of patients with dementia with Lewy bodies. Alzheimer's Res. Ther. 2019, 11, 8-10. [CrossRef]

192. Bibl, M.; Mollenhauer, B.; Esselmann, H.; Lewczuk, P.; Klafki, H.W.; Sparbier, K.; Smirnov, A.; Cepek, L.; Trenkwalder, C.; Rüther, E.; et al. CSF amyloid- $\beta$-peptides in Alzheimer's disease, dementia with Lewy bodies and Parkinson's disease dementia. Brain 2006, 129, 1177-1187. [CrossRef]

193. Hall, S.; Surova, Y.; Öhrfelt, A.; Blennow, K.; Zetterberg, H.; Hansson, O. Longitudinal measurements of cerebrospinal fluid biomarkers in Parkinson's disease. Mov. Disord. 2016, 31, 898-905. [CrossRef] [PubMed]

194. Wennström, M.; Hall, S.; Nägga, K.; Londos, E.; Minthon, L.; Hansson, O. Cerebrospinal fluid levels of IL-6 are decreased and correlate with cognitive status in DLB patients. Alzheimer's Res. Ther. 2015, 7, 63. [CrossRef]

195. Hansson, O.; Hall, S.; Öhrfelt, A.; Zetterberg, H.; Blennow, K.; Minthon, L.; Nägga, K.; Londos, E.; Varghese, S.; Majbour, N.K.; et al. Levels of cerebrospinal fluid $\alpha$-synuclein oligomers are increased in Parkinson's disease with dementia and dementia with Lewy bodies compared to Alzheimer's disease. Alzheimer's Res. Ther. 2014, 6, 25. [CrossRef]

196. Stewart, T.; Liu, C.; Ginghina, C.; Cain, K.C.; Auinger, P.; Cholerton, B.; Shi, M.; Zhang, J. Cerebrospinal fluid $\alpha$-synuclein predicts cognitive decline in Parkinson disease progression in the DATATOP cohort. Am. J. Pathol. 2014, 184, 966-975. [CrossRef]

197. Bougea, A.; Stefanis, L.; Paraskevas, G.P.; Emmanouilidou, E.; Efthymiopoulou, E.; Vekrelis, K.; Kapaki, E. Neuropsychiatric symptoms and $\alpha$-Synuclein profile of patients with Parkinson's disease dementia, dementia with Lewy bodies and Alzheimer's disease. J. Neurol. 2018, 265, 2295-2301. [CrossRef]

198. Rossi, M.; Candelise, N.; Baiardi, S.; Capellari, S.; Giannini, G.; Orrù, C.D.; Antelmi, E.; Mammana, A.; Hughson, A.G.; Calandra-Buonaura, G.; et al. Ultrasensitive RT-QuIC assay with high sensitivity and specificity for Lewy body-associated synucleinopathies. Acta Neuropathol. 2020, 140, 49-62. [CrossRef]

199. Bongianni, M.; Ladogana, A.; Capaldi, S.; Klotz, S.; Baiardi, S.; Cagnin, A.; Perra, D.; Fiorini, M.; Poleggi, A.; Legname, G.; et al. $\alpha$-Synuclein RT-QuIC assay in cerebrospinal fluid of patients with dementia with Lewy bodies. Ann. Clin. Transl. Neurol. 2019, 6, 2120-2126. [CrossRef] 
200. Majbour, N.K.; Vaikath, N.N.; Eusebi, P.; Chiasserini, D.; Ardah, M.; Varghese, S.; Haque, M.E.; Tokuda, T.; Auinger, P.; Calabresi, P.; et al. Longitudinal changes in CSF alpha-synuclein species reflect Parkinson's disease progression. Mov. Disord. 2016, 31, 1535-1542. [CrossRef] [PubMed]

201. Factor, S.A.; Scullin, M.K.; Sollinger, A.B.; Land, J.O.; Wood-Siverio, C.; Zanders, L.; Freeman, A.; Bliwise, D.L.; McDonald, W.M.; Goldstein, F.C. Cognitive correlates of hallucinations and delusions in Parkinson's disease. J. Neurol. Sci. 2014, 347, 316-321. [CrossRef] [PubMed]

202. Førland, M.G.; Öhrfelt, A.; Dalen, I.; Tysnes, O.B.; Blennow, K.; Zetterberg, H.; Pedersen, K.F.; Alves, G.; Lange, J. Evolution of cerebrospinal fluid total $\alpha$-synuclein in Parkinson's disease. Park. Relat. Disord. 2018, 49, 4-8. [CrossRef]

203. Mollenhauer, B.; Caspell-Garcia, C.J.; Coffey, C.S.; Taylor, P.; Singleton, A.; Shaw, L.M.; Trojanowski, J.Q.; Frasier, M.; Simuni, T.; Iranzo, A.; et al. Longitudinal analyses of cerebrospinal fluid $\alpha$-Synuclein in prodromal and early Parkinson's disease. Mov. Disord. 2019, 34, 1354-1364. [CrossRef] [PubMed]

204. Delgado-Alvarado, M.; Gago, B.; Gorostidi, A.; Jiménez-Urbieta, H.; Dacosta-Aguayo, R.; Navalpotro-Gómez, I.; Ruiz-Martínez, J.; Bergareche, A.; Martí-Massó, J.F.; Martínez-Lage, P.; et al. Tau/ $\alpha$-synuclein ratio and inflammatory proteins in Parkinson's disease: An exploratory study. Mov. Disord. 2017, 32, 1066-1073. [CrossRef]

205. Van Steenoven, I.; Majbour, N.K.; Vaikath, N.N.; Berendse, H.W.; van der Flier, W.M.; van de Berg, W.D.J.; Teunissen, C.E.; Lemstra, A.W.; El-Agnaf, O.M.A. $\alpha$-Synuclein species as potential cerebrospinal fluid biomarkers for dementia with lewy bodies. Mov. Disord. 2018, 33, 1724-1733. [CrossRef]

206. Eusebi, P.; Giannandrea, D.; Biscetti, L.; Abraha, I.; Chiasserini, D.; Orso, M.; Calabresi, P.; Parnetti, L. Diagnostic utility of cerebrospinal fluid $\alpha$-synuclein in Parkinson's disease: A systematic review and meta-analysis. Mov. Disord. 2017, 32, 1389-1400. [CrossRef]

207. García-Ayllón, M.S.; Monge-Argilés, J.A.; Monge-García, V.; Navarrete, F.; Cortés-Gómez, M.A.; Sánchez-Payá, J.; Manzanares, J.; Gasparini-Berenguer, R.; Leiva-Santana, C.; Sáez-Valero, J. Measurement of CSF $\alpha$-synuclein improves early differential diagnosis of mild cognitive impairment due to Alzheimer's disease. J. Neurochem. 2019, 150, 218-230. [CrossRef]

208. Mavroudis, I.; Petridis, F.; Kazis, D. Cerebrospinal fluid, imaging, and physiological biomarkers in dementia with Lewy bodies. Am. J. Alzheimer's Dis. Other Dement. 2019, 34, 421-432. [CrossRef]

209. Atik, A.; Stewart, T.; Zhang, J. Alpha-synuclein as a biomarker for Parkinson's disease. In Proceedings of the Brain Pathology; Blackwell Publishing Ltd.: Hoboken, NJ, USA, 2016; Volume 26, pp. 410-418.

210. Williams, S.M.; Schulz, P.; Sierks, M.R. Oligomeric $\alpha$-synuclein and $\beta$-amyloid variants as potential biomarkers for Parkinson's and Alzheimer's diseases. Eur. J. Neurosci. 2016, 43, 3-16. [CrossRef]

211. Perra, D.; Bongianni, M.; Novi, G.; Janes, F.; Bessi, V.; Capaldi, S.; Sacchetto, L.; Tagliapietra, M.; Schenone, G.; Morbelli, S.; et al. Alpha-synuclein seeds in olfactory mucosa and cerebrospinal fluid of patients with dementia with Lewy bodies. Brain Commun. 2021, 3, 1-11. [CrossRef]

212. Stefani, A.; Iranzo, A.; Holzknecht, E.; Perra, D.; Bongianni, M.; Gaig, C.; Heim, B.; Serradell, M.; Sacchetto, L.; Garrido, A.; et al. Alpha-synuclein seeds in olfactory mucosa of patients with isolated REM sleep behaviour disorder. Brain 2021, 144, 1118-1126. [CrossRef]

213. Zhao, Y.; Xin, Y.; Meng, S.; He, Z.; Hu, W. Neurofilament light chain protein in neurodegenerative dementia: A systematic review and network meta-analysis. Neurosci. Biobehav. Rev. 2019, 102, 123-138. [CrossRef]

214. Chaudhry, A.; Houlden, H.; Rizig, M. Novel fluid biomarkers to differentiate frontotemporal dementia and dementia with Lewy bodies from Alzheimer's disease: A systematic review. J. Neurol. Sci. 2020, 415, 116886. [CrossRef] [PubMed]

215. Lin, Y.S.; Lee, W.J.; Wang, S.J.; Fuh, J.L. Levels of plasma neurofilament light chain and cognitive function in patients with Alzheimer or Parkinson disease. Sci. Rep. 2018, 8, 17368. [CrossRef] [PubMed]

216. Schade, S.; Mollenhauer, B. Biomarkers in biological fluids for dementia with Lewy bodies. Alzheimer's Res. Ther. 2014, 6, 72. [CrossRef]

217. King, E.; O’Brien, J.; Donaghy, P.; Williams-Gray, C.H.; Lawson, R.A.; Morris, C.M.; Barnett, N.; Olsen, K.; Martin-Ruiz, C.; Burn, D.; et al. Inflammation in mild cognitive impairment due to Parkinson's disease, Lewy body disease, and Alzheimer's disease. Int. J. Geriatr. Psychiatry 2019, 34, 1244-1250. [CrossRef]

218. King, E.; O’brien, J.T.; Donaghy, P.; Morris, C.; Barnett, N.; Olsen, K.; Martin-Ruiz, C.; Taylor, J.P.; Thomas, A.J. Peripheral inflammation in mild cognitive impairment with possible and probable Lewy body disease and Alzheimer's disease. Int. Psychogeriatr. 2019, 31, 551-560. [CrossRef]

219. King, E.; Thomas, A. Systemic inflammation in Lewy body diseases a systematic review. Alzheimer Dis. Assoc. Disord. 2017, 31, 346-356. [CrossRef]

220. Maetzler, W.; Stapf, A.K.; Schulte, C.; Hauser, A.K.; Lerche, S.; Wurster, I.; Schleicher, E.; Melms, A.; Berg, D. Serum and cerebrospinal fluid uric acid levels in lewy body disorders: Associations with disease occurrence and amyloid- $\beta$ pathway. $J$. Alzheimer's Dis. 2011, 27, 119-126. [CrossRef]

221. Sommer, I.; Griebler, U.; Kien, C.; Auer, S.; Klerings, I.; Hammer, R.; Holzer, P.; Gartlehner, G. Vitamin D deficiency as a risk factor for dementia: A systematic review and meta-analysis. BMC Geriatr. 2017, 17, 1-13. [CrossRef]

222. Zhou, Z.; Zhong, S.; Liang, Y.; Zhang, X.; Zhang, R.; Kang, K.; Qu, H.; Xu, Y.; Zhao, C.; Zhao, M. Serum uric acid and the risk of dementia: A systematic review and meta-analysis. Front. Aging Neurosci. 2021, 13, 625690. [CrossRef] 
223. Erkkinen, M.G.; Kim, M.O.; Geschwind, M.D. Clinical neurology and epidemiology of the major neurodegenerative diseases. Cold Spring Harb. Perspect. Biol. 2018, 10, a033118. [CrossRef]

224. Oh, Y.S.; Kim, J.S.; Park, H.E.; Song, I.U.; Park, J.W.; Yang, D.W.; Son, B.C.; Lee, S.H.; Lee, K.S. Association between urine protein/creatinine ratio and cognitive dysfunction in Lewy body disorders. J. Neurol. Sci. 2016, 362, 258-262. [CrossRef] [PubMed]

225. Henderson, M.X.; Sedor, S.; McGeary, I.; Cornblath, E.J.; Peng, C.; Riddle, D.M.; Li, H.L.; Zhang, B.; Brown, H.J.; Olufemi, M.F.; et al. Glucocerebrosidase activity modulates neuronal susceptibility to pathological $\alpha$-synuclein insult. Neuron 2020, 105, 822-836.e7. [CrossRef] [PubMed]

226. Chiasserini, D.; Biscetti, L.; Eusebi, P.; Salvadori, N.; Frattini, G.; Simoni, S.; De Roeck, N.; Tambasco, N.; Stoops, E.; Vanderstichele, $\mathrm{H}$.; et al. Differential role of CSF fatty acid binding protein 3, $\alpha$-synuclein, and Alzheimer's disease core biomarkers in Lewy body disorders and Alzheimer's dementia. Alzheimer's Res. Ther. 2017, 9, 1-12. [CrossRef] [PubMed]

227. Müller, S.K.; Bender, A.; Laub, C.; Högen, T.; Schlaudraff, F.; Liss, B.; Klopstock, T.; Elstner, M. Lewy body pathology is associated with mitochondrial DNA damage in Parkinson's disease. Neurobiol. Aging 2013, 34, 2231-2233. [CrossRef] [PubMed]

228. Moccia, M.; Picillo, M.; Erro, R.; Vitale, C.; Longo, K.; Amboni, M.; Santangelo, G.; Palladino, R.; Capo, G.; Orefice, G.; et al. Presence and progression of non-motor symptoms in relation to uric acid in de novo Parkinson's disease. Eur. J. Neurol. 2015, 22, 93-98. [CrossRef]

229. Annanmaki, T.; Pessala-Driver, A.; Hokkanen, L.; Murros, K. Uric acid associates with cognition in Parkinson's disease. Park. Relat. Disord. 2008, 14, 576-578. [CrossRef]

230. Chatzikonstantinou, S.; McKenna, J.; Karantali, E.; Petridis, F.; Kazis, D.; Mavroudis, I. Electroencephalogram in dementia with Lewy bodies: A systematic review. Aging Clin. Exp. Res. 2020, 33, 1197-1208. [CrossRef]

231. Bonanni, L.; Thomas, A.; Tiraboschi, P.; Perfetti, B.; Varanese, S.; Onofrj, M. EEG comparisons in early Alzheimer's disease, dementia with Lewy bodies and Parkinson's disease with dementia patients with a 2-year follow-up. Brain 2008, 131, 690-705. [CrossRef]

232. Stylianou, M.; Murphy, N.; Peraza, L.R.; Graziadio, S.; Cromarty, R.; Killen, A.; O' Brien, J.T.; Thomas, A.J.; LeBeau, F.E.N.; Taylor, J.P. Quantitative electroencephalography as a marker of cognitive fluctuations in dementia with Lewy bodies and an aid to differential diagnosis. Clin. Neurophysiol. 2018, 129, 1209-1220. [CrossRef]

233. Law, Z.K.; Todd, C.; Mehraram, R.; Schumacher, J.; Baker, M.R.; LeBeau, F.E.N.; Yarnall, A.; Onofrj, M.; Bonanni, L.; Thomas, A.; et al. The role of EEG in the diagnosis, prognosis and clinical correlations of dementia with Lewy bodies-A systematic review. Diagnostics 2020, 10, 616. [CrossRef]

234. Bonanni, L.; Perfetti, B.; Bifolchetti, S.; Taylor, J.P.; Franciotti, R.; Parnetti, L.; Thomas, A.; Onofrj, M. Quantitative electroencephalogram utility in predicting conversion of mild cognitive impairment to dementia with Lewy bodies. Neurobiol. Aging 2015, 36, 434-445. [CrossRef]

235. Pase, M.P.; Himali, J.J.; Grima, N.A.; Beiser, A.S.; Satizabal, C.L.; Aparicio, H.J.; Thomas, R.J.; Gottlieb, D.J.; Auerbach, S.H.; Seshadri, S. Sleep architecture and the risk of incident dementia in the community. Neurology 2017, 89, 1244-1250. [CrossRef]

236. Ferman, T.J.; Boeve, B.F.; Smith, G.E.; Lin, S.C.; Silber, M.H.; Pedraza, O.; Wszolek, Z.; Graff-Radford, N.R.; Uitti, R.; Van Gerpen, J.; et al. Inclusion of RBD improves the diagnostic classification of dementia with Lewy bodies. Neurology 2011, 77, 875-882. [CrossRef]

237. Garcia-Ptacek, S.; Kramberger, M.G. Parkinson disease and dementia. J. Geriatr. Psychiatry Neurol. 2016, 29, 261-270. [CrossRef]

238. Garcia-Ptacek, S.; Farahmand, B.; Kareholt, I.; Religa, D.; Cuadrado, M.L.; Eriksdotter, M. Mortality risk after dementia diagnosis by dementia type and underlying factors: A cohort of 15,209 patients based on the swedish dementia registry. J. Alzheimer's Dis. 2014, 41, 467-477. [CrossRef]

239. Akbar, U.; McQueen, R.B.; Bemski, J.; Carter, J.; Goy, E.R.; Kutner, J.; Johnson, M.J.; Miyasaki, J.M.; Kluger, B. Prognostic predictors relevant to end-of-life palliative care in Parkinson's disease and related disorders: A systematic review. J. Neurol. Neurosurg. Psychiatry 2021, 92, 629-636. [CrossRef]

240. Kramberger, M.G.; Auestad, B.; Garcia-Ptacek, S.; Abdelnour, C.; Olmo, J.G.; Walker, Z.; Lemstra, A.W.; Londos, E.; Blanc, F.; Bonanni, L.; et al. Long-term cognitive decline in dementia with lewy bodies in a large multicenter, international cohort. J. Alzheimer's Dis. 2017, 57, 787-795. [CrossRef]

241. Mueller, C.; Soysal, P.; Rongve, A.; Isik, A.T.; Thompson, T.; Maggi, S.; Smith, L.; Basso, C.; Stewart, R.; Ballard, C.; et al. Survival time and differences between dementia with Lewy bodies and Alzheimer's disease following diagnosis: A meta-analysis of longitudinal studies. Ageing Res. Rev. 2019, 50, 72-80. [CrossRef]

242. Moylett, S.; Price, A.; Cardinal, R.N.; Aarsland, D.; Mueller, C.; Stewart, R.; O’Brien, J.T. Clinical presentation, diagnostic features, and mortality in dementia with lewy bodies. J. Alzheimer's Dis. 2019, 67, 995-1005. [CrossRef]

243. Alvarez, M.V.G.; Evidente, V.G.H. Understanding drug-induced parkinsonism: Separating pearls from oy-sters. Neurology 2008, 70, 32-34. [CrossRef]

244. Wang, H.F.; Yu, J.T.; Tang, S.W.; Jiang, T.; Tan, C.C.; Meng, X.F.; Wang, C.; Tan, M.S.; Tan, L. Efficacy and safety of cholinesterase inhibitors and memantine in cognitive impairment in Parkinson's disease, Parkinson's disease dementia, and dementia with Lewy bodies: Systematic review with meta-analysis and trial sequential analysis. J. Neurol. Neurosurg. Psychiatry 2015, 86, 135-143. [CrossRef] [PubMed] 
245. Taylor, J.P.; McKeith, I.G.; Burn, D.J.; Boeve, B.F.; Weintraub, D.; Bamford, C.; Allan, L.M.; Thomas, A.J.; O’Brien, J.T. New evidence on the management of Lewy body dementia. Lancet Neurol. 2020, 19, 157-169. [CrossRef]

246. Dementia: Assessment, Management and Support for People Living with Dementia and Their Carers. NICE guideline [NG97]. Available online: https:/ / www.nice.org.uk/guidance/ng97 (accessed on 17 June 2021).

247. Stinton, C.; McKeith, I.; Taylor, J.P.; Lafortune, L.; Mioshi, E.; Mak, E.; Cambridge, V.; Mason, J.; Thomas, A.; O’Brien, J.T. Pharmacological management of lewy body dementia: A systematic review and meta-analysis. Am. J. Psychiatry 2015, 172, 731-742. [CrossRef] [PubMed]

248. Knight, R.; Khondoker, M.; Magill, N.; Stewart, R.; Landau, S. A systematic review and meta-analysis of the effectiveness of acetylcholinesterase inhibitors and memantine in treating the cognitive symptoms of dementia. Dement. Geriatr. Cogn. Disord. 2018, 45, 131-151. [CrossRef] [PubMed]

249. Goldman, J.G.; Goetz, C.G.; Brandabur, M.; Sanfilippo, M.; Stebbins, G.T. Effects of dopaminergic medications on psychosis and motor function in dementia with Lewy bodies. Mov. Disord. 2008, 23, 2248-2250. [CrossRef]

250. Matsunaga, S.; Kishi, T.; Iwata, N. Combination therapy with zonisamide and antiparkinson drugs for Parkinson's disease: A meta-analysis. J. Alzheimer's Dis. 2017, 56, 1229-1239. [CrossRef]

251. Murata, M.; Odawara, T.; Hasegawa, K.; Iiyama, S.; Nakamura, M.; Tagawa, M.; Kosaka, K. Adjunct zonisamide to levodopa for DLB parkinsonism: A randomized double-blind phase 2 study. Neurology 2018, 90, e664-e672. [CrossRef]

252. Samudra, N.; Patel, N.; Womack, K.B.; Khemani, P.; Chitnis, S. Psychosis in Parkinson disease: A review of etiology, phenomenology, and management. Drugs Aging 2016, 33, 855-863. [CrossRef]

253. Seppi, K.; Ray Chaudhuri, K.; Coelho, M.; Fox, S.H.; Katzenschlager, R.; Perez Lloret, S.; Weintraub, D.; Sampaio, C.; Chahine, L.; Hametner, E.M.; et al. Update on treatments for nonmotor symptoms of Parkinson's disease-An evidence-based medicine review. Mov. Disord. 2019, 34, 180-198. [CrossRef]

254. Hershey, L.A.; Coleman-Jackson, R. Pharmacological management of dementia with Lewy bodies. Drugs Aging 2019, 36, 309-319. [CrossRef]

255. Chan, P.C.; Lee, H.H.; Hong, C.T.; Hu, C.J.; Wu, D. REM sleep behavior disorder (RBD) in dementia with lewy bodies (DLB). Behav. Neurol. 2018, 2018, 9421098. [CrossRef]

256. Goldman, J.G.; Forsberg, L.K.; Boeve, B.F.; Armstrong, M.J.; Irwin, D.J.; Ferman, T.J.; Galasko, D.; Galvin, J.E.; Kaufer, D.; Leverenz, J.; et al. Challenges and opportunities for improving the landscape for Lewy body dementia clinical trials. Alzheimer's Res. Ther. 2020, 12, 137. [CrossRef]

257. Siderowf, A.; Aarsland, D.; Mollenhauer, B.; Goldman, J.G.; Ravina, B. Biomarkers for cognitive impairment in Lewy body disorders: Status and relevance for clinical trials. Mov. Disord. 2018, 33, 528-536. [CrossRef] 